\title{
The Cronobacter genus: ubiquity and diversity
}

Authors: Eva Kucerova, Susan Joseph, Stephen Forsythe

School of Science and Technology

Nottingham Trent University

Clifton Lane

Nottingham, UK

NG11 8NS

Corresponding author:

Prof SJ Forsythe. School of Science and Technology, Nottingham Trent University, Clifton Lane, Nottingham, UK. NG11 8NS. Tel: 0115 8483529. Fax: 01158486636.

Email: Stephen.forsythe@,ntu.ac.uk

\section{Authors' contribution:}

Eva Kucerova - performed research, and wrote paper

Susan Joseph - performed research

Stephen Forsythe - designed research, and wrote paper

\section{Keywords:}

Cronobacter, E. sakazakii, infant formula, neonates, food safety 


\section{Abstract}

2 Members of the Cronobacter genus (formerly Enterobacter sakazakii) have become associated with 3 neonatal infections and in particular contaminated reconstituted infant formula. However this is only 4 one perspective of the organism since the majority of infections are in the adult population, and the 5 organism has been isolated from the enteral feeding tubes of neonates on non-formula diets. In recent

6 years methods of detection from food and environmental sources have improved, though accurate

7 identification has been problematic. The need for robust identification is essential in order to

8 implement recent Codex Alimentarius Commission (2008) and related microbiological criteria for

9 powdered infant formula (PIF; intended target age 0-6 months). Genomic analysis of emergent

10 pathogens is of considerable advantage in both improving detection methods, and understanding the

11 evolution of virulence. One ecosystem for Cronobacter is on plant material which may enable the

12 organism to resist desiccation, adhere to surfaces, and resist some antimicrobial agents. These traits

13 may also confer survival mechanisms of relevance in food manufacturing and also virulence

14 mechanisms. 
1

2 Food safety is important to everyone, and especially the highly vulnerable members of our society.

3 This article concerns the bacterial genus Cronobacter which can cause severe illness in the highly

4 vulnerable neonates, infants and the elderly. In recent years this group of organisms have gone from

5

6

7 Cronobacter is a genus within the Enterobacteriaceae family and is closely related to the

8 curiosity to notoriety and this article aims to deliver a balanced viewpoint on their importance and an overview of our knowledge Enterobacter and Citrobacter genera. It has come to prominence due to its association with severe neonatal infections (necrotizing enterocolitis, septicaemia and meningitis) which can be fatal. As neonates are frequently fed reconstituted PIF, which is not a sterile product, this potential vector has been the focus of attention for reducing infection risk to neonates as the number of exposure routes is limited. It should be noted however that such neonatal infections are rare, and not all have been associated with reconstituted formula ingestion. In fact (a) breast milk is also not sterile, (b) $C$. malonaticus LMG $23826^{\mathrm{T}}$ (type strain) was isolated from a breast abscess, (c) Cronobacter has been isolated from breast milk, (d) breast milk from mastic mothers is used to feed neonates, (e) the organism has been isolated from enteral feeding tubes from neonates on non-formula diets and (f) the majority of Cronobacter infections, albeit less severe, are in the adult population.

To date the raised awareness of the organism has focussed on infant infections and resulted in changes in the microbiological criteria for PIF and reconstitution procedures. In other words, there have been required changes on two sides of the same coin; manufacturing practices and hygienic preparation practices. Such requirements need regulatory enforcement and support, but must be based on robust reliable information. Consequently there have been three FAO/WHO risk assessment meetings on the microbiological safety of PIF (FAO/WHO 2004, FAO/WHO 2006, FAO/WHO 2008). Those identified as being at high risk of Cronobacter infection are neonates (especially low birth weight) for whom their source of nutrition will be limited to breast milk, fortified breast milk, or breast milk replacement. Hence hygienic preparation of feed is essential due to their immature immune system 
1

2

3

4

5

and lack of competing intestinal flora. Key advice from these FAO/WHO risk assessments was that PIF should be reconstituted with water $>70^{\circ} \mathrm{C}$, minimise any storage time by not preparing in advance and if storage for short periods is necessary then the temperature should be $<5^{\circ} \mathrm{C}$. The high water temperature will drastically reduce the number of vegetative bacteria present, and minimising the storage period will reduce the multiplication of any surviving organisms. These recommendations have been well addressed by the WHO 'Guidelines for the safe preparation, storage and handling of powdered infant formula' which are available online and can be downloaded using the URL given in the Reference section. The FAO/WHO 2004 expert committee recommended that research should be promoted to gain a better understanding of the taxonomy, ecology, virulence and other characteristics of Cronobacter. This article addresses many of these topics, using our recent findings on the genomic analysis of the organism and similarities with closely related organisms as well as issues of detection and consumer protection.

Taxonomy and identification schemes

\section{Taxonomy of Cronobacter}

Initially the organism was regarded as a pigmented variety of Enterobacter cloacae. In 1974, Brenner showed that the pigmented strains had $<50 \%$ homology with non-pigmented strains and it was suggested that they should comprise a new species (Brenner 1974). E. sakazakii was later distinguished from E. cloacae based on DNA-DNA hybridisation, pigment production, biotype assignment and antimicrobial resistance (Farmer 1980, Izard, Richar et al. 1983), the species name being derived from the Japanese bacteriologist Riichi Sakazaki. DNA-DNA hybridization values were $41 \%$ and $54 \%$ for Citrobacter freundii and E. cloacae, respectively, which were used as representatives of the Citrobacter and Enterobacter genera (Farmer 1980). The results warranted the recognition of a separate species and, as they were phenotypically closer to E. cloacae, they were kept in the Enterobacter genus. Additional phenotypic analysis led to the description of 15 E. sakazakii 
biogroups, with biotype 1 being the most common (Farmer 1980). At this point, there was no clear evidence of the generic assignment of E. sakazakii to the Enterobacter genus, however.

Since the 1980s, bacterial systematics has increasingly used DNA sequencing for its analysis and for determining relatedness. Analysis of both partial 16S rDNA and hsp60 gene sequencing by Iversen and Forsythe in 2004 showed that E. sakazakii isolates formed at least four distinct clusters which probably represented different closely related species (Iversen, Waddington et al. 2004). The 15 different biogroups fitted into the 4 clusters, and a 16th biogroup was added in subsequent work (Iversen, Waddington et al. 2006). However, full taxonomic revision required considerable further analysis for substantiation. The Cronobacter genus was defined first in 2007 and revised in 2008 (Iversen, Lehner et al. 2007, Iversen, Mullane et al. 2008). Differentiation between the newly defined Cronobacter species is primarily based on genotypic (DNA-based) analysis and is largely supported by biochemical traits (Table 1) (Iversen, Lancashire et al. 2006). With a few exceptions, the former biotypes and genomogroups correspond with the new species; as shown in Table 1. The genus Cronobacter is currently composed of C. sakazakii, C. malonaticus, C. turicensis, C. muytjensii, and C. dublinensis. Distinguishing between the two species C. sakazakii and C. malonaticus has been problematic and there are two primary reasons for this. Firstly, the use of biotype profile to designate the species was not totally robust as a few of the biotype index strains were themselves assigned the wrong species (Baldwin, Loughlin et al. 2009). Secondly, there are 7 copies of the rDNA gene in Cronobacter and intrageneric differences can lead to uncertain and inconsistent base calls.

Since members of the Cronobacter genus were formerly known as the single species Enterobacter sakazakii, this name was used in publications before mid-2007. Subsequently it is uncertain which specific Cronobacter species were referred to in many pre-2007 publications. The majority of isolated strains are usually C. sakazakii, and it is probable that this has been the species of major study to date. For our part, we have tried to give cross-references for strains in our own publications to assist readers, and are available on request. Accurate bacterial taxonomy is essential for regulatory control since the detection methods must be based on a thorough understanding of the diversity of the target organism. A number of early methods were based on small numbers of poorly 
1

2

3

\section{Identification schemes}

5 The Codex Alimentarius Commission (2008) microbiological criteria are applied to PIF with the

characterised, even misidentified, strains and therefore are not necessarily reliable for their stated purpose. intended age $<6$ months (Codex Alimentarius Commission (CAC) 2008). Hence a number of methods for the recovery of desiccation-stressed Cronobacter cells from this group of products have been developed. As the organism has only been reported at low numbers $(<1 \mathrm{cfu} / \mathrm{g})$, a large volume of material needs to be tested. Subsequently the Codex Alimentarius Commission requirement is to test thirty $\log$ quantities, and therefore presence/absence testing of PIF is applied rather than direct enumeration. Initial Cronobacter detection methods were reminiscent of the stages for Salmonella isolation from milk powders. In brief, the steps were pre-enrichment $(225 \mathrm{ml}$ water or BPW $+25 \mathrm{~g}$ formula), enrichment (EE broth), plate on to VRBG agar, pick off 5 colonies to TSA and identify phenotypically any yellow pigmented colonies. It is now recognised that there are a number of limitations with this method. There is no initial selection for Cronobacter, instead any Enterobacteriaceae could be enriched in EE broth and grow on VRBG agar leading to possible overgrowth of Cronobacter. Furthermore, not all Cronobacter strains are pigmented and so could be overlooked on TSA plates. Finally phenotype databases did not adequately cover the genus resulting in conflicting results between commercial kits. These days improved methods employ chromogenic agars, updated phenotyping databases, along with DNA-based identification and fingerprinting techniques. Cronobacter has a notable resistance to osmotic stresses, which may be linked to its ecology, and this trait has been used in the design of improved enrichment broths; modified lauryl sulphate broth containing $0.5 \mathrm{M} \mathrm{NaCl}$ and Cronobacter screening broth with $10 \%$ sucrose. The use of chromogenic agar (primarily based on the $\alpha$-glucosidase reaction) to differentiate Cronobacter from other Enterobacteriaceae present on the plate was a major improvement. The $\alpha$-glucosidase activity as a test differentiating the then E. sakazakii from E. cloacae had been reported in the early days by 
1 Harry Muytjens (Muytjens, van der Ros-van de Repe. et al. 1984). As well as testing PIF,

2 environmental samples are taken from the production environment as well as from ingredients

3 (especially starches and other plant-derived material). In addition, production facilities and processes

4 are already designed to control enteric pathogens, especially Salmonella.

5 Commercial companies producing phenotyping kits have been updating their databases due to

6 the taxonomic revision, for example, the former E. sakazakii Preceptrol ${ }^{\mathrm{TM}}$ strain ATCC $\mathbb{B} 51329$ has

7 been reclassified as C. muytjensii and should not be confused with C. sakazakii. The specificity of

8 some formerly E. sakazakii DNA-based PCR probes to the diverse Cronobacter genus needs to be re-

9 evaluated, and new species-specific Cronobacter probes have been developed.

16S rDNA sequences have been traditionally used to determine phylogenetic relationships

between organisms including Enterobacteriaceae. However 16S rDNA sequencing is of limited use for very closely related organisms because of minor differences in the rDNA sequence. 16S rRNA gene sequencing can distinguish between the Cronobacter species as shown in Figure 1. Earlier difficulties in distinguishing between $C$. sakazakii and C. malonaticus was possibly due to polymorphic nucleotide sites and depended on the operator interpretation of the sequencing chromatograms for those loci. Additionally there is difficulty using biotyping to define the Cronobacter species as some strains defined as particular biotype index strains were misassigned their species. 16S rDNA sequence analysis has been applied to early strains of E. sakazakii and other misidentifications include:

1. Fatal case of neonatal sepsis infection in neonatal intensive care unit by E. sakazakii, reidentified as E. cloacae (Caubilla-Barron, Hurrell et al. 2007)

2. Neonatal intensive care unit outbreak of E. sakazakii, reidentified as E. hormaechei (Townsend, Hurrell et al. 2008)

3. Quinolone-resistant E. sakazakii strain, reidentified as E. hormaechei (Poirel, Nordmann et al. 2007) 


\section{Molecular typing methods}

4 Czerwicka et al. 2005)

4. Oligo-polysaccharide structure for E. sakazakii, strain re-identified as E. ludwiggi (Szafranek,

Although it is generally possible to differentiate Cronobacter species by biochemical profiling, molecular methods are increasingly used as a more rapid and reliable tool to study bacterial genomic diversity and to track sources of infection. Since the organism is ubiquitous, typing schemes are required both for epidemiological and environmental investigation. As given above, initially 15 biogroups of Cronobacter were defined with biogroup 1 being the most common. These divisions, however, are not specific enough for epidemiological investigations. Instead, initial procedures used plasmid profiling, chromosomal restriction endonuclease analysis and multilocus enzyme electrophoresis (Clark, Hill et al. 1990, Nazarowec-White, Farber 1999). This was followed by the application of Random Amplified Polymorphic DNA (RAPD) ribotyping, pulsed-field gel electrophoresis (PFGE), and MLVA (multiple-locus variable-number tandem repeat analysis) (Mullane, Ryan et al. 2008). To date, PFGE with two restriction enzymes (Xbal and Spe 1) is the most common method (Caubilla-Barron, Hurrell et al. 2007). The technique is widely employed and can be used for transnational investigations, as per PulseNet, since the gel results can be electronically analyzed (http://www.cdc.gov/pulsenet/). PFGE is considered the gold standard for genetic typing and is recommended to be used in surveillance and investigations of sources of outbreaks.

Typing Cronobacter to understand its diversity has led to the development of a multilocus sequence typing (MLST) scheme which is available online (www.pubMLST.org/cronobacter) (Baldwin, Loughlin et al. 2009). The sequencing of protein coding genes is a useful, more discriminatory alternative to partial $16 \mathrm{~S}$ rDNA sequencing (ca. 528 nucleotide length), especially as unlinked sequences from multiple protein-coding genes are used. The Cronobacter MLST analysis is based on 7 housekeeping genes; ATP synthase beta chain ( $a t p \mathrm{D})$, elongation factor $\mathrm{G}$ ( fus A), glutaminyl-tRNA synthetase $(g \ln \mathrm{S})$, glutamate synthase large subunit $(g l t \mathrm{~B})$, DNA gyrase subunit B (gyrB), translation initiation factor IF-2 (inf $\mathrm{B})$ and phosphoenolpyruvate synthase $\mathrm{A}(p p s \mathrm{~A})$. The 7 
1 sequenced alleles can be concatenated together to give $>3000$ nucleotide for phylogenetic analysis

2 (Fig 2). This is 6 times the length of the commonly used partial 16S rDNA sequences, and has the

3 additional advantage of considerably greater number of variable loci. The initial publication was

4 focussed on C. sakazakii and C. malonaticus due to the reported difficulties in distinguishing between

5 them (Baldwin, Loughlin et al. 2009). The 7 allele phylogenetic tree (Fig 2) is comparable to the 16S

6 tree (Fig 1). The MLST analysis has revealed a remarkably strong clonal nature in Cronobacter. Of

7 particular note, is that this study showed that sequence types (ST) existed which were primarily

8 associated with infant formula (ST3), another both infant formula and clinical isolations (ST4), and

9 another which was primarily composed of clinical isolates (ST8). The strains analysed were widely

10 geographically, temporally and source distributed, some of which could be traced over a 50 year

11 period. These clones may reflect different ecologies of the organism. ST8 indicates that there may be

12 a source of Cronobacter which is not PIF associated. Therefore to focus on PIF analysis following a

13 Cronobacter outbreak on a NICU may lead to oversight of the true source of the infection. As given

14 above, the MLST scheme is accessible online and has been extended to cover all Cronobacter species.

15 The scheme will be of considerable use in the future for choosing representative Cronobacter strains

16 when undertaking further studies.

18 Ecology and physiological aspects

\section{Plant-associated traits and sources}

Iversen and Forsythe hypothesized that the Cronobacter species might be of plant origin due to physiological features such as the production of a polysaccharide capsule, production of a yellow pigment and its desiccation resistance (Iversen, Forsythe 2003). These traits may enable the organism to stick to plant leaves, protect against oxygen radicals from sunlight exposure, and survive dry periods including autumn. About $80 \%$ of Cronobacter strains produce a non-diffusible, yellow pigment on Tryptone Soya Agar at $25^{\circ} \mathrm{C}$. Pigment production is temperature dependent, and even 
1 fewer strains produce it at $37^{\circ} \mathrm{C}$. As given above, the organism probably colonizes plant material and

2 the yellow carotenoid-based pigmentation may protect it from sunlight-generated oxygen radicals.

3

A productive source of Cronobacter strains are fresh or dried herbs and spices with $\sim 30 \%$ incidence. In fact an early patent for a food thickener was material extracted from E. sakazakii isolated from Chinese tea (Harris, Oriel 1989, Scheepe-Leberkuhne, Wagner 1986). In order to provide evidence for the plant origin of Cronobacter, Schmid et al. investigated biochemical traits associated with plant microorganisms in nine strains representing the then recognised five Cronobacter species (Schmid, Iversen et al. 2009). All strains were able to solubilise mineral phosphate, produce indole acetic acid and produce siderophores. The strains were also able to endophytically colonise tomato and maize roots. The authors concluded that plants may be the natural habitat of Cronobacter spp. and that the rhizosphere might act as a reservoir of the bacterium.

The plant association of Cronobacter may account for physiological traits such as surviving spray drying and prolonged periods in dry materials (ie. starches), and presence in ingredients that are added to PIF without additional heat treatment (FAO/WHO 2004, FAO/WHO 2006). Unlike most other Enterobacteriaceae, the organism can persist in PIF for 2 years (Caubilla-Barron, Hurrell et al. 2007). It is notable that, when the E. sakazakii species was defined, it included a strain which had been isolated from dried milk in 1960. Therefore, possibly Cronobacter has been present in dried milk products for many decades. For a fuller review of desiccation survival mechanisms please see Forsythe \& Osaili (Osaili, Forsythe 2009).

Cronobacter have the ability to survive osmotic stress and desiccation (Riedel, Lehner 2007, Osaili, Forsythe 2009). They are able to take up osmoprotectants including trehalose (via phosphotrasferase system, PTS), glycine, betaine, proline, spermidine, and putrescine using ABC transporters.

Since the organism is probably plant associated it is not surprising that the organism can be isolated from a wide range of environments, including water, soil, herbs and spices, and a variety of processed foods and fresh produce (Friedemann 2007). The resistance to plant essential oils may be 
1 linked to efflux pumps which contribute to the organism's resistance to osmotic pressure, and can be

2 of use in the design of selective media.

3

As given above, MLST has revealed the organism may have a more complex ecology with nonplant ecosystems. The bacterium has been isolated from the hospital environment and clinical samples; cerebrospinal fluid, blood, bone marrow, sputum, urine, inflamed appendix, neonatal enteral

6 feeding tubes and conjunctivae. Asymptomatic human carriage (intestines and throat) have also been reported. The bacterium has been isolated from factories producing milk powder, household vacuum cleaning bags and also from household utensils used for the reconstitution of PIF (Muytjens, Roelofs-

9 Willemse et al. 1988, Bar-Oz, Preminger et al. 2001, Block, Peleg et al. 2002, Kandhai, Reij et al. 2004)

\section{Powdered infant formula, follow up formula and weaning foods}

Cronobacter was first associated with contaminated PIF by Muytjens et al. in 1988 (Muytjens,

Roelofs-Willemse et al. 1988) when it was isolated from prepared formula and reconstitution equipment. They reported $52.2 \%(n=141)$ of PIF samples from 35 countries contained Enterobacteriaceae, with 14\% containing Cronobacter spp. (Muytjens, Roelofs-Willemse et al. 1988). A more recent international survey for Cronobacter and related organisms in PIF, follow up formula and infant foods was conducted by 8 laboratories in 7 countries in response to the call for data in preparation for the FAO/WHO 2008 risk assessment. In total, 290 products were analysed using a standardised procedure. Cronobacter was isolated from $3 \%(n=91)$ follow up formulae and $12 \%(n=199)$ infant foods and drinks (Chap, Jackson et al. 2009). The few reported quantitative studies do not show any samples with Cronobacter at levels $>1$ cell/g PIF. In fact $<1$ cell in $100 \mathrm{~g}$ may be more representative and explains why large sample volumes $(30 \times 10 \mathrm{~g})$ are required for testing. Hence, the need to consider opportunities for extrinsic bacterial contamination and multiplication during formula preparation. Due to the ubiquitous presence of Cronobacter and its 
1 resistance to dry conditions, contamination of food products including PIF is difficult to avoid.

2 Cronobacter does posses the gene encoding the universal stress protein UspA, which is also found in

3 other closely related Enterobacteriaceae (E. coli, Enterobacter cloacae, Citrobacter koseri, and

4 Pantoea spp.). In E. coli the protein is induced following both heat and osmotic shock. Hence it may

5 be important in the survival of Cronobacter during manufacturing processes and the cross-induction

6 of other protection mechanisms.

\section{Capsule and biofilm formation}

8 Cronobacter do not have the pgaABCD locus which in E. coli promotes its binding to abiotic surfaces

9 and encodes for $\beta-1,6-N$-acetyl-D-glucosamine. Instead, the organism often produces a

10 heteropolysaccharide capsule composed of glucuronic acid, D-glucose, D-galactose, D-fucose and D-

11 mannose. Strains from NICU outbreaks produce so much capsular material that on milk agar plates

12 the colonies drip onto the lid of inverted Petri dishes (Caubilla-Barron, Hurrell et al. 2007). This material has been patented for use as a thickening agent in foods (Scheepe-Leberkuhne, Wagner 1986, Harris, Oriel 1989). The capsular material, induced under nitrogen-limited conditions, could facilitate the organism's attachment to plant surfaces. Combined with a tolerance to desiccation, this gives the organism an armoury to colonize plant material and maybe survive harsh, environmental conditions. These traits may also contribute to the organism's presence in starches used in the manufacture of infant formula and persistence during the manufacturing process. The organism attaches to surfaces, forming biofilms that are resistant to cleaning and disinfectant agents, and the organism has been isolated as part of the mixed flora biofilm in enteral feeding tubes of neonates not fed PIF (Hurrell,

21 Kucerova et al. 2009b). stainless steel (Iversen, Forsythe 2003). Furthermore, Cronobacter has been reported to attach and form biofilm on glass and polyvinyl chloride (Lehner, Riedel et al. 2005). All of these materials are commonly used for infant-feeding and food preparation equipment and, if contaminated, may increase the risk of infection. Beuchat et al. reported that the ability of Cronobacter to form a biofilm is 
1 affected by the composition of the media (Beuchat, Kim et al. 2009), and that it is enhanced by infant

2 formula components. The infant formula composition can also increase Cronobacter resistance to

3 disinfectants, as shown by Beuchat et al. who examined the effect of thirteen disinfectants commonly

4 used in infant formula preparation areas (Kim, Ryu et al. 2007). Populations of Cronobacter cells

$5 \quad$ suspended in water ( $c$ a. $7 \log \mathrm{CFU} / \mathrm{ml})$ decreased to undetectable levels $(<0.3 \log \mathrm{CFU} / \mathrm{ml})$ within $1-$

65 min of treatment with disinfectants, whereas numbers of cells in reconstituted PIF diminished by

7 only $0.02-3.69 \log \mathrm{CFU} / \mathrm{ml}$ after treatment for $10 \mathrm{~min}$. Furthermore, cells attached to stainless steel

8 were less resistant to disinfectants. It is clear that the ability of Cronobacter to attach to surfaces,

9 form biofilms, and resist dry stress conditions contribute to the risk of Cronobacter ingestion.

10 Moreover, the composition of PIF has a strong protective effect on the survival of Cronobacter.

Cronobacter appear to have the carbon storage regulatory (Csr) system as evident by the

12 presence of CsrA in both C. sakazakii and C. turicensis genomes. Although its regulatory role in

13 Cronobacter is unknown at present, its role in E. coli has been well established. CsrA is an RNA-

binding protein that binds to the untranslated leader sequences of target mRNAs and alters their translation and stability. It represses stationary phase processes, including glycogen synthesis and catabolism, gluconeogenesis, and biofilm formation. It also activates glycolysis, motility, and biofilm dispersal. Repression of biofilm formation by CsrA involves the synthesis and catabolism of intracellular glycogen. Therefore biofilm formation in Cronobacter is probably linked to central carbon metabolism.

Finally, high levels of heat-stable lipopolysaccharide (endotoxin) in infant formula may enhance the translocation of Cronobacter across both the intestines and the blood-brain barrier, and therefore increase the risk of bacteraemia in neonates (Townsend, Caubilla Barron et al. 2007). Levels of endotoxin vary 500-fold in PIF. The chemical structure of oligopolysaccharide from three Cronobacter species; C. sakazakii BAA-894, 767, C. malonaticus and C. muytjensii have been derived (Czerwicka, Forsythe et al. 2010, MacLean, Pagotto et al. 2009a, MacLean, Pagotto et al. 2009b, MacLean, Vinogradov et al. 2009). The material is branched in C. sakazakii and linear in $C$. 


\section{Temperature response}

4

muytjensii. Whether the surface structure is important in virulence remains to be determined but may serve as a basis for serotyping and other characterisation methods.

Cronobacter can grow over a wide temperature range. Due to interest in the organism and infant infections, growth and death rates have been determined in reconstituted infant formula. At room temperature $\left(21^{\circ} \mathrm{C}\right)$, Cronobacter had a doubling time of $40-94$ minutes. The lowest permissible growth temperature is near refrigeration $\left(\sim 5^{\circ} \mathrm{C}\right)$ and therefore the organism may grow following prolonged storage or poor temperature control. The maximum growth temperature $\left(44-47^{\circ} \mathrm{C}\right)$ is strain dependent, and the C. sakazakii type strain (ATCC $29544^{\mathrm{T}}$ ) is reported not to grow above $42^{\circ} \mathrm{C}$ (Nazarowec-White \& Farber 1997) the temperature used for the ISO/TS 22964 isolation method Recent studies show that $C$. turicensis grows at $<5^{\circ} \mathrm{C}$ which is lower than other Cronobacter species and has a lower maximum temperature (Caubilla-Barron, Kucerova et al. 2009).

Decimal reduction times and z-values vary considerably between strains, i.e. $\mathrm{D}_{55} 2-49$ minutes, z-values $2-14^{\circ} \mathrm{C}$ (Caubilla-Barron, Kucerova et al. 2009). Early studies inferred the organism was very thermotolerant. However, subsequent work clarified that the organism was less thermotolerant than L. monocytogenes (Nazarowec-White and Farber 1999). Nevertheless, the organism can survive spray drying albeit with a considerable reduction in viability, and the surviving cells may be severely damaged (Caubilla-Barron, Kucerova et al. 2009). The organism's tolerance to drying has been well noted, and it can survive for two years desiccated in infant formula and then rapidly grow on reconstitution (Barron, Forsythe 2007).

The first and second FAO/WHO meetings (2004 and 2006) reviewed the organisms associated with neonatal infections, those found in PIF, and also those that had been epidemiologically linked (FAO/WHO 2006, FAO/WHO 2004). Subsequently, Salmonella and Cronobacter were designated Category A (Clear evidence of causality), and other named Enterobacteriaceae and Acinetobacter were in Category B (Causality plausible, but not yet 
1 demonstrated). In order to reduce the number of intrinsic bacteria and limit bacterial growth, the

2 FAO/WHO (2004 and 2006) expert committees proposed that PIF be reconstituted at temperatures no

3 cooler than $70^{\circ} \mathrm{C}$, and that it is used immediately rather than stored (FAO/WHO 2006, FAO/WHO

4 2008). As stated earlier, a common feature in a number of outbreaks has been a lack of adequate

5 hygienic preparation and temperature control of the reconstituted infant formula. A second outcome

6 from the FAO/WHO meetings was the production of an online risk model;

7 http://www.mramodels.org/ESAK/default.aspx. The model allows the user to compare the level of

8 risk between different levels of contamination and reconstitution practices. The model was based on

9 growth and death kinetic data for a limited number of Cronobacter strains. We recently extended the

10 Risk Model to cover all organisms in Categories A \& B; Cronobacter species, Salmonella, other

11 named Enterobacteriaceae and Acinetobacter spp. It can be accessed from the UK FSA web site at

$12 \mathrm{http} / / / \mathrm{www}$.foodbase.org.uk/results.php?f_category_id=\&f_report_id=395. The data was generated

13 using casein- and whey-based formulas as the type of formula affects bacterial lag times, growth and

14 death rates.

As referred to above, the WHO guidelines for hygienic preparation of PIF are aimed at reducing the number of bacteria in the reconstituted product by using hot water and limiting the time available for any survivors to multiply. However a wider perspective is that neonates are frequently feed via enteral feeding tubes. These tubes are in place for prolonged periods (even several days) to reduce distress to the neonate by the gagging reaction. However Cronobacter, and other opportunistic pathogens can attach and colonise these tubes which are at $37^{\circ} \mathrm{C}$, and at regular intervals receive fresh feed (Hurrell, Kucerova et al. 2009a, Hurrell, Kucerova et al. 2009b). This scenario is applicable to all neonates with nasogastric tubes, and not only those on reconstituted PIF. In fact Cronobacter and other Enterobacteriaceae have been isolated from such tubes in intensive care units from neonates receiving breast milk and various other feeding regimes at levels up to $10^{7}$ cfu per tube (Hurrell, Kucerova et al. 2009a, Hurrell, Kucerova et al. 2009b). Therefore hygienic practices and avoidance of temperature abuse are vitally important regardless of the type of feed. 


\section{Cronobacter virulence}

\section{Adult and neonate infections}

3 It may be a surprise to some readers but Cronobacter infections are not unique to neonates. In fact

4 5 they occur in all age groups, with the greater incidence in the more immuno-compromised very young and elderly. A major difference between the age groups is the severity of infection in neonates.

Infections caused by Cronobacter in adults comprise a wide range of symptoms from conjunctivitis, biliary sepsis, urosepsis and appendicitis to wound infection and pneumonia. Infections in neonates include infant meningitis and necrotizing enterocolitis (Gurtler, Kornacki et al. 2005). Adult patients at increased risk include those previously treated with antibiotics, immuno-compromised and elderly patients, those with medical implants or with acute, chronic, or serious illnesses (Sanders and Sanders 1997, Pitout, Moland et al. 1997).

According to the FAO/WHO (2008) around the world there have been 120 documented Cronobacter cases and at least 27 deaths (FAO/WHO 2008). This is undoubtedly an underestimate. In the USA, the reported Cronobacter infection incidence rate is 1 per 100000 infants. This incidence rate increases to 9.4 per 100000 in infants of very low birth weight, i.e. $<1.5 \mathrm{~kg}$. Symptoms in neonates include necrotising enterocolitis (NEC), septicaemia and meningitis. The former is noninvasive (and is multifactorial), whereas in septicaemia and meningitis the organism has attached and invaded presumably through the intestinal epithelial layer. NEC is a common gastrointestinal illness in neonates and can be caused by a variety of bacterial pathogens. It is characterized by ischaemia, bacterial colonisation of the intestinal tract, and increased levels of proteins in the gastrointestinal lumen. The incidence of NEC is $2-5 \%$ of premature infants and $13 \%$ in those weighing $<1.5 \mathrm{~kg}$ at birth. It is 10 times more common in infants fed formula compared with those fed breast milk (Lucas, Cole 1990). Necrotizing enterocolitis has a high mortality rate; $15-25 \%$ of cases (Henry, Moss 2009). Cronobacter has been implicated as a causative agent of necrotizing enterocolitis (NEC), but its role in the pathogenesis of the disease is somewhat unclear. There are reports of Cronobacter 
1 isolation from babies who developed NEC (van Acker, de Smet et al. 2001, Caubilla-Barron, Hurrell

2 et al. 2007). This suggests that there is an association between Cronobacter occurrence and NEC,

3 although until recently, the organism has not been conclusively proven to cause the disease.

Infant meningitis can be caused by a variety of bacterial pathogens, including Cronobacter and

5 its close relatives Enterobacter cloacae and Citrobacter koseri. Cronobacter-related meningitis is

6 characterized by a mortality rate of $40-80 \%$ and generally a very poor clinical outcome. The

7 bacterium causes cystic changes, abscesses, fluid collection, brain infarctions, hydrocephalus, necrosis

8 of brain tissue and liquefaction of white cerebral matter. Patients surviving Cronobacter-related

9 meningitis often suffer from severe neurological sequelae, such as hydrocephalus, quadriplegia and

10 retarded neural development (Lai 2001). The infection usually arises between the fourth and fifth day after birth and it can be fatal within hours to days following the first clinical signs (Muytjens, Zanen et al. 1983). Compared with patients suffering from Cronobacter-induced enterocolitis, infants in whom meningitis developed tend to have normal gestational age and birth weight (Bowen and Braden 2006).

\section{Sources of infection}

15 While the source of contamination in Cronobacter-related outbreaks has not always been confirmed, breast milk substitutes (one group of PIF products) have been epidemiologically or microbiologically established as the source of infection in a number of cases (Muytjens, Zanen et al. 1983, Biering, Karlsson et al. 1989, Simmons, Gelfand et al. 1989, Clark, Hill et al. 1990, Muytjens and Kollee 1990, van Acker, de Smet et al. 2001, Weir 2002, Iversen and Forsythe 2003). A strong link between the presence of Cronobacter in formula feeding and an outbreak of Cronobacter infection was established by Center for Disease Control and Prevention in 2002 following the outbreak in a neonatal intensive care unit (NICU) in Tennessee in 2001. In this outbreak, one neonate died from Cronobacter-induced meningitis and further 10 cases of Cronobacter colonisation were found on the same unit. Later investigation revealed that the formula fed to the infant in Tennessee was in fact a formula that was not intended for neonates. 
Infections have been directly linked to reconstituted PIF which may have been contaminated intrinsically or during preparation and administration. A common feature in some of these outbreaks is the opportunity for temperature abuse of the prepared feed, which would permit bacterial growth. In reported outbreaks in France and USA, the neonates were fed using perfusion devices whereby the reconstituted PIF is slowly pumped at ambient temperature into the neonate through an enteral feeding tube (Himelright, Harris et al. 2002, Caubilla-Barron, Hurrell et al. 2007). Using this procedure there is the possibility of bacterial multiplication in the syringe leading to the ingestion of large numbers of Cronobacter by the neonate. The neonate has an immature immune system and a low intestinal microflora density. Consequently, if a large number of Cronobacter cells were ingested they would not be outcompeted by the resident intestinal flora. Following invasion of the intestinal cells, the lack of a developed immune system could make the neonate more prone to systemic infection. No infectious dose has been determined for neonates. Animal studies by Pagotto, Nazarowec-White et al. (2003) and Richardson et al. (2009) have used large numbers of Cronobacter cells $\left(\sim 10^{8}\right)$ for infection studies. Whether this number is reflective of that necessary for neonates is uncertain, but it does contrast with the number of cells reported in contaminated PIF $(<1 \mathrm{cfu} / \mathrm{g})$, and may therefore indicate the role of temperature abuse in enabling bacterial multiplication.

It is pertinent to note that the bacterium is isolated from the tracheae and has been recovered from the feeding tubes of neonates fed breast milk and ready-to-feed formula, not infant formula (Hurrell, Kucerova et al. 2009b). Therefore wider sources of the organism during an outbreak need to be investigated, not just the use of PIF. Infants can be colonized by more than one strain of Cronobacter, and therefore multiple isolates need to be characterized by PFGE in epidemiological investigations (Caubilla-Barron, Hurrell et al. 2007).

Bowen and Bradden have reported that there are a number of neonatal cases which have no links with the ingestion of infant formula (Bowen and Braden 2006). Therefore in epidemiological investigations multiple sources should be sampled. Breast milk can contain the bacterium, and the $C$. malonaticus type strain (LMG $23826^{\mathrm{T}}$ ) was isolated from a breast abscess. In some countries breast milk from mothers with mastitis is still fed to the neonate. The organism has also been isolated from 
1 hospital air, human intestines and throats. So control of microbiological content of PIF will not

2 necessarily totally remove the risk of neonate infection by this bacterium.

\section{Virulence factors}

4 All Cronobacter species have been associated with clinical infections in infants or adults and are

5 considered potentially pathogenic. To date, isolates from infected neonates have been limited to only

6 three species; C. sakazakii, C. malonaticus and C. turicensis (Kucerova et al. 2010). These species

7 can invade human intestinal cells, replicate in macrophages and invade the blood-brain barrier. It is

8 known that Cronobacter strains and species vary in their virulence (Caubilla-Barron et al. 2007). In

9 vitro studies have shown that bacterial attachment and invasion of mammalian intestinal cells,

10 macrophage survival and serum resistance is comparable with E. cloacae and Cit. freundii, but less

11 than that for Salmonella Typhimurium (Townsend, Hurrell et al. 2007). Strains from C. sakazakii and

12 C. malonaticus showed higher invasion of Caco-2 (human cell line) than other Cronobacter species.

13 Similarily C. sakazakii and C. malonaticus survive and replicate in macrophages inside phagosomes,

14 whereas $C$. muytjensii die, and C. dublinensis is serum sensitive. Virulence also varies within the $C$.

15 sakazakii species. This was determined from epidemiological studies of an NICU outbreak in France

where the clinical outcome of three C. sakazakii pulsetypes varied with only one pulsetype causing the three deaths (Caubilla-Barron, Hurrell et al. 2007). Additionally this variation in virulence is supported by mammalian tissue culture studies (Pagotto, Nazarowec-White et al. 2003, Townsend, Hurrell et al. 2007, Townsend, Hurrell et al. 2008) and appears to have been confirmed by recent MLST studies (Baldwin, Loughlin et al. 2009). OmpA is produced by Cronobacter and has been used as an identification trait. This protein has been extensively studied in E. coli $\mathrm{K} 1$ as contributes to the organism's serum resistance, adhesion to host cells and invasion of brain microvascular endothelial cells. It is logical to predict that it also has a role in Cronobacter penetrating the blood-brain barrier. However the mechanism leading to the destruction of the brain cells is unknown and could, in part, be a host response. Cronobacter may invade the tissues using pathogenic secretory factors (elastases, glycopeptides, endotoxins, collagenases and proteases) which increase the permeability of the blood- 
1 brain barrier and allow the organism to gain access to the nutrient-rich cerebral matter (Iversen and

2 Forsythe 2003). Only a limited number of animal studies have been undertaken on C. sakazakii,

3 principally by Pagotto and colleagues (Pagotto, Nazarowec-White et al. 2003) and Richardson and

4 colleagues (Richardson, Lambert et al. 2009) but these have confirmed the variation within the

5 species.

6

7

In Cronobacter meningitis there is gross destruction of the brain, leading sadly to either death (40-80\% of cases) or severe neurological damage. This pathogenesis is different to that caused by both Neisseria meningitidis and neonatal meningitic E. coli. Some reports suggest a similarity between the tropism of Cronobacter and the closely related organism Cit. koseri for invasion and infection of the central nervous system (Willis and Robinson 1988, Burdette and Santos 2000). Kline noted that brain abscesses caused by Cronobacter and Cit. koseri were morphologically similar and may be due to similar virulence mechanisms (Kline 1988). Although the production of an enterotoxin by some Cronobacter strains described by Pagotto et al. (Pagotto, Nazarowec-White et al. 2003) is widely acknowledged, the genes encoding the putative toxin have yet to be identified. The $C$. sakazakii type strain ATCC $29544^{\mathrm{T}}$ showed no enterotoxin production in their study, which confirms that there are considerable differences in virulence among Cronobacter strains and that some strains may be non-pathogenic. Kothary et al. characterized a zinc metalloprotease, zpx, which was unique to 135 Cronobacter strains tested, which could allow the bacterium to penetrate the blood-brain barrier and cause meningitis (Kothary, McCardell et al. 2007). The protein is found in all Cronobacter species (Kucerova, Clifton et al. 2010), although there is some sequence variation (Kothary, McCardell et al. 2007). Although C. muytjensii has not been associated with neonatal infections, one strain (ATCC 51329 ${ }^{\mathrm{T}}$, source unknown) has been used in animal studies to demonstrate its potential to infect neonates (Mittal, Wang et al. 2009).

Townsend et al. showed that Cronobacter can attach to intestinal Caco 2 cells and survive in macrophages, but the invasion mechanism remains unknown (Townsend, Hurrell et al. 2007). (Kucerova, Clifton et al. 2010) referred to a prophage encoding a protein homologous to the Eae adhesion protein. This however only encodes for a small portion of the protein and probably has not 
1 physiological relevance. Kim and Loessner suggested that the invasion of Cronobacter to Caco2

2 cells may be receptor-mediated, as the bacterial invasion showed characteristics of saturation kinetics

3 (Kim and Loessner 2008). The authors also concluded that bacterial de novo protein synthesis was

4 required for invasion. In the same study, pretreatment of Caco2 cells with an actin polymerization

5 inhibitor resulted in decreased invasiveness of Listeria monocytogenes and Salmonella Typhimurium,

6 but enhanced the invasiveness of Cronobacter. The authors hypothesized that this enhancement was

7 due to the disruption of tight junction, a membrane-associated structure that acts as a barrier against

8 the molecular exchange between epithelial cells. This was confirmed when the disruption of the tight

9 junction by EGTA significantly increased the invasive properties of Cronobacter. They also speculated that frequent lipopolysaccharide contamination of PIF that is known to disrupt tight

11 junctions might contribute to the invasiveness of Cronobacter (Kim and Loessner 2008).

Townsend et al. studied seven C. sakazakii strains associated with the largest reported NICU outbreak with the most reported deaths to date. All strains were able to attach and invade intestinal cells Caco2 more than E coli K12 and Salmonella Enteritidis (Townsend, Hurrell et al. 2008). Two strains (767 and 701), both associated with fatal cases of meningitis and NEC, showed the highest invasion rates. These two strains were also able to replicate within macrophages, while all other strains survived inside macrophages for at least $48 \mathrm{~h}$ (Townsend, Hurrell et al. 2008).

\section{Antibiotic susceptibility}

When an infection by Cronobacter occurs, it is essential to provide rapid antibiotic treatment. Although the bacterium tends to be more sensitive to most antibiotics compared to other Enterobacteriaceae, its increasing resistance to some antibiotics has proven problematic. Cronobacter related infections have been traditionally treated with ampicillin combined with gentamycin or chloramphenicol (Lai 2001). Unfortunately, the organism has developed resistance to ampicillin (Muytjens, Zanen et al. 1983, Lai 2001) and gentamicin use is limited as it fails to reach sufficient concentrations in the cerebral spinal fluid (Iversen and Forsythe 2003). In 1980, all strains tested by Farmer were susceptible to ampicillin (Farmer 1980). In 2001, Lai described five cases of 
1 Cronobacter infection in which one or more of the isolates were resistant to ampicillin and most

2 cephalosporins of $1^{\text {st }}$ and $2^{\text {nd }}$ generation (Lai 2001). Kim et al. reported frequent resistance of

3 Cronobacter food isolates to ampicillin and cephalotin (Kim, Jang et al. 2008). For this reason, the

4 shift to carbapenems or $3^{\text {rd }}$ generation cephalosporins with an aminoglycoside or trimethoprim with

5 sulfamethoxazole was proposed. This treatment improved the outcome of Cronobacter meningitis,

6 but may also have caused the increase in resistance to these antimicrobials (Lai 2001).

$7 \quad$ Initial reports concerning the ability of Cronobacter to produce $\beta$-lactamases gave conflicting

8 results. The presence of B-lactamases in Cronobacter was reported in a study by Pitout et al. when all

9 tested strains were positive for Bush group 1 ß-lactamase (cephalosporinase) (Pitout, Moland et al.

10 1997). In 2001, Lai reported increasing $\beta$-lactamase production among Cronobacter strains (Lai

11 2001). Similarly, Block and colleagues reported that all Cronobacter isolates tested were $\beta$-lactamase

12 positive (Block, Peleg et al. 2002). However, Stock and Wiedemann did not find any evidence of $\beta$ -

13 lactam production in the 35 Cronobacter strains tested (Stock and Wiedemann 2002). The

14 discrepancy in the results might be due to the different selection of strains, the limited number of

15 strains used, as well as differences in the experimental protocol. Also, some Enterobacter strains

16 express $\beta$-lactamases at very low levels, which might have not been detectable by the methods used.

\section{Genome studies}

Genome description of $C$. sakazakii and C. turicensis

19 The genome of the C. sakazakii strain (BAA-894) from the formula associated with the neonate infection in Tennessee (Himelright, Harris et al. 2002) has been sequenced and published (Kucerova, Clifton et al. 2010). This can be compared with the unpublished genome sequence of $C$. turicensis strain z3032 which was also associated with a neonatal infection and has been sequenced by the Technische Universitaet Muenchen, Germany. The sequences are available online (RefSeq numbers NC_009778 and NC_013282 respectively). Additionally, the proteome of the same C. turicensis strain has been published, which will considerably assists in our understanding the organism 
1 (Carranza, Hartmann et al. 2009). The genome of C. sakazakii comprises a $4.4 \mathrm{Mbp}$ chromosome and

2 two plasmids (31 and $131 \mathrm{kbp}$ ). The C. turicensis z3032 genome is similar; chromosomal size 4.4

3 Mbp, three plasmids (20,50 and $140 \mathrm{kbp}$ ). The \%GC of both Cronobacter strains is $57-58 \%$, which

4 is greater than that of the closely related organism Enterobacter cloacae. Both Cronobacter strains

5 have a large plasmid (131 and $140 \mathrm{kbp}$ ) with the same $\% \mathrm{GC}$ ratio as the chromosome and a large

6 number of genes, as well as smaller plasmids with a lower (51\%) GC content. Despite the apparent

7 similarities between the plasmids with respect to sizes and \%GC content, caution should be exercised

8 as plasmids do vary between species and in early work plasmid profiling was used for

9 epidemiological purposes (Clark, Hill et al. 1990). Three putative prophage genomes and three

10 putative prophage fragments were identified in C. sakazakii BAA-894. These have been described in

11 detail already (Kucerova, Clifton et al. 2010). C. turicensis z3032 genome also contains at least three

12 putative prophages as identified by Prophinder (Lima-Mendez, Van Helden et al. 2008). The

13 presence of these phage regions is important as prophages can play an important role in evolution of

14 bacteria by introducing novel genes of different biological functions and contribute to their virulence

15 properties.

17 Comparative genomic hybridisation studies of the Cronobacter species

18 Of the 4,382 annotated genes, $55 \%$ (2404) were present in all C. sakazakii strains, and $43 \%$ (1899) were present in all Cronobacter species (Kucerova, Clifton et al. 2010). Note that when genes defined as intermediate are included, the core gene set for C. sakazakii species constitutes $80.9 \%$ (3547) genes and core gene for Cronobacter genus includes $75.3 \%$ (3301) genes. The vast majority of these shared genes are predicted to encode cellular essential functions such as energy metabolism, biosynthesis, DNA, RNA and protein synthesis, cell division and membrane transport. The proportion of genes absent from test strains compared with C. sakazakii BAA-894 ranged from 10.3\% (453) in $C$. sakazakii strain 20 to 17.1\% (751) in C. muytjensii (Kucerova, Clifton et al. 2010). 
Whole-genome clustering based on the comparative genomic hybridization data by Kucerova and colleagues revealed that Cronobacter strains formed two distinct phylogenetic clusters. All $C$. sakazakii strains formed one cluster, whereas C. malonaticus, C. turicensis, C. dublinensis and C. malonaticus formed a second, separate cluster. Within C. sakazakii, strains 701 and 767 were the most closely related and clustered together with strain 20. Previously, strains 701 and 767 were shown to belong to the same pulse field gel electrophoresis restriction digestion type (Caubilla-Barron, Hurrell et al. 2007). Although the clinical details of the source of C. sakazakii strain 20 are unknown, the strain belongs to MLST sequence type 4 (as do 701 and 767). This is a stable clone of $C$. sakazakii isolated from both PIF and clinical sources (Baldwin, Loughlin et al. 2009). C. sakazakii strain ATCC $29544^{\mathrm{T}}$ (species type strain) formed a separate branch within the C. sakazakii cluster. The remaining Cronobacter species formed sub-clusters: $C$. malonaticus clustered with $C$. turicensis and $C$. dublinensis grouped with C. muytjensii.

The differences in gene content that contributed to the separation of Cronobacter species into different branches were further analysed. Thirteen gene clusters that were present in all C. sakazakii strains but absent in some or all other Cronobacter species were identified and denoted SR1-SR13. The presence of these regions in different Cronobacter species is summarised in Table 2. SR 1 (ESA_00257 - ESA_00258) encodes a putative toxin/antitoxin pair RelE/RelB, which, if encoded on plasmids, may help to maintain a plasmid in a bacterial population. When encoded on a chromosome, however, the toxin/antitoxin system probably represents selfish DNA. SR2 (ESA_01116 ESA_01119) is a cluster of genes encoding a complete ABC-type multidrug efflux system. ESA_01116 encodes a multidrug efflux pump, ESA_01117 encodes an outer membrane efflux protein from a family including TolC, ESA_01118 is the permease component of the ABC-type system and ESA_01119 encodes the ATPase component of the efflux system. SR3 (ESA_01448 - ESA_01450) encodes three proteins from the family of fatty acid desaturases. Members of this family are involved in cholesterol biosynthesis and biosynthesis of a plant cuticular wax, but may be implicated in other biosynthetic pathways. SR4 (ESA_02125 - ESA_02129) encodes a diverse group of proteins where no common assignment to a pathway or mechanism could be found; it includes acetyltransferases, a 
1 transcriptional regulator from the lysR family and a putative esterase/lipase. ESA_02129 encodes a

2 serine protease inhibitor ecotin; ecotins from species that come into contact with the mammalian immune system like E.coli, Y. pestis and P. aeruginosa have been shown to protect bacteria against the effects of neutrophil elastase (Eggers, Murray et al. 2004). SR5 (ESA_02538 - ESA_02542) is a cluster of fimbrial genes (Described in 5.3). The genes in SR6 (ESA_02544 - ESA_02547) are involved in the metabolism of beta-glucosides. ESA_02544 is a transcriptional antiterminator from the BglG family, which is involved in positive control of the utilization of different sugars by transcription antitermination (Bardowski, Ehrlich et al. 1994). ESA_02545 encodes a kinase than converts beta-glucosides to 6-phospho-beta-glucosides and ESA_02546 encodes a 6-phospho-betaglucosidase (EC 3.2.1.86) specific to arbutin-6 phosphate and salicilin-6-phosphate. ESA_02547 also encodes 6-phospho-beta-glucosidase (EC 3.2.1.86) which may have the same or similar function as ESA_02546. SR7 (ESA_02549 - ESA_02553) may encode a complete ABC multidrug transport system. SR8 (ESA_02616-ESA_02618) contains genes related to mannose metabolism. ESA_02616 encodes an alpha-mannosidase, ESA_02617 is a gene taking part in the mannosyl-D-glycerate uptake via the phosphotransferase system and ESA_02618 encodes a mannosyl-D-glycerate transport/metabolism system repressor. SR9 (ESA_02795 - ESA_02799) is a fimbrial cluster (described in 5.3). Genes in SR10 (ESA_03301-ESA_03305) encode proteins involved in the metabolism of fructose and mannose via the PTS and a putative porin KdgM. ESA_03301 encodes an isomerizing glucosamine-fructose-6-phosphate aminotransferase. ESA_03302, located on the opposite strand to the rest of the genes in this cluster, encodes an oligogalacturonate-specific porin protein (KdgM). ESA_03303 encodes a fructose-specific II component of the PTS system FruA, which converts fructose to fructose-1-phosphate. ESA_03304 encodes an alpha-mannosidase involved in mannose degradation. ESA_03305 encodes a phosphomannose isomerase, which converts Dmannose to beta-D-glucose-6-phosphate. SR11 (ESA_03609-ESA_03613) is a cluster of genes also putatively involved in metabolism of mannose and other sugars. ESA_03609 encodes a putative betagalactosidase. Genes ESA_03610 and ESA_03612 encode genes involved in the $N$-acetylneuraminate and $N$-acetylmannosamine degradation pathway. ESA_03610 encodes a $\mathrm{N}$-acetylmannosamine kinase and ESA_03611 encodes a N-acetylneuraminate lyase. Gene ESA_03612 encodes a 
1 transcriptional regulator from the GntR family. SR 12 (ESA_04067 - ESA_04073) is a cluster of

2 fimbrial genes (described in 5.3). SR13 (ESA_04101 - ESA_04106) encodes genes that may be

3 involved in the O-PS biogenesis. ESA_04102 encodes a glycosyltransferase involved in cell wall

4 biogenesis, ESA_04103 encodes a putative O-antigen ligase or a related enzyme. Genes ESA_04104

5 and ESA_04105 encode glycosyltransferases and ESA_04105 encodes a putative lipopolysaccharide

6 heptosyltransferase III. This cluster is a part of a larger cluster of genes involved in LPS biogenesis,

7 however, it is not related to the $\mathrm{O}$-antigen cluster defined by Mullane and colleagues (Mullane,

8 O'Gaora et al. 2008). The genes from this cluster were absent in C. malonaticus, but present or

9 intermediate in all other Cronobacter species, but the putative O-antigen ligase (ESA_04103) was

10 absent from all Cronobacter species except C. sakazakii.

11 Variations in virulence traits as revealed by CGH are covered in more detail in the following section.

12 The chemical structure of oligo-polysaccharide (O-antigen) in three Cronobacter species has

13 been determined and shown to be compositionally and structurally different. It is therefore

14 predictable that the biosynthetic pathways will vary across the genus and this has been confirmed by

$15 \mathrm{CGH}$. The gene cluster corresponding to the O-antigen cluster described by (Mullane, O'Gaora et al.

16 2008) (ESA_01177-ESA_01189) was examined. The genetic architecture of the O-antigen cluster in

17 the sequenced C. sakazakii BAA-894 corresponds to the serotype 0:1 as defined by Mullane and

18 colleagues. According to our CGH data, two of the genes in this region, galF (ESA_01177) and $r f b$ B

19 (ESA_01178) are conserved among all Cronobacter strains tested except C. sakazakii 696, whereas

20 the rest of the genes from the $\mathrm{O}$-antigen locus are highly divergent; its genes were not sufficiently

21 similar to be detected by microarray hybridization in any other Cronobacter strains. This correlates

22 with the findings of Mullane and colleagues, who showed that both serotypes $0: 1$ and $0: 2$ had the

23 two genes $g a l \mathrm{~F}$ and $r f b \mathrm{~B}$ in common, whereas the rest of the gene cluster content differed between the

24 two serotypes. 


\section{Virulence traits and survival mechanisms}

2 Since Cronobacter is associated with neonates and infants, the availability of iron in milk or formula

3 could be an important virulence trait. A list of known iron assimilation mechanisms was compiled

4 and their presence in different Cronobacter species was evaluated based on the available CGH data

5 (Kucerova, Clifton et al. 2010). All Cronobacter strains examined by CGH possess complete operons

6 for enterobactin synthesis (entABCDEFS) and enterobactin receptor and transport (fepABCDEG),

7 except C. dublinensis, in which fepE is absent (Table 4). All Cronobacter species except $C$.

8 muytjensii also possess a complete operon for aerobactin synthesis iucABCD and its receptor iutA.

9 The operon for salmochelin synthesis is missing in all Cronobacter species (Table 4). The strong genetic similarity between C. sakazakii and Citrobacter koseri, as well as urinary pathogenic E. coli is evident from the presence of all genes for enterobactin and aerobactin synthesis in these organisms. $C$. sakazakii can cause urinary tract infections, though to date this aspect has not been studied in any detail.

The route of infection is probably through attachment and invasion of the intestinal cells, and therefore genes encoding surface appendages such as pili (fimbriae) have been studied. Four putative fimbriae clusters were identified in the genome of $C$. sakazakii BAA-894, some of which were mentioned previously in (Healy, Huynh et al. 2009). These are Cluster 1 (ESA_01976 - ESA_01970), cluster 2 (ESA_02538 - ESA_02542), cluster 3 (ESA_02795 - ESA_02799) and cluster 4 (ESA_04067 - ESA_04073) (Table 3). Further analysis of the comparative hybridization data showed that three of the four putative fimbrial clusters (Clusters 2,3 and 4) were C. sakazakii specific, i.e. were classified as present or intermediate in all five strains of $C$. sakazakii, but were absent in C. muytjensii, C. dublinensis, C. turicensis, and C. malonaticus. Cluster 1 was present only in the reference strain and C. sakazakii strain 2, which suggests that it is strain specific. The genetic content of all fimbriae clusters was most similar to the type I chaperone/usher-assembled pilus system as defined in (Kline, Dodson et al. 2010). Genes for pilin FimA, chaperone FimC and usher FimD have been found in all four putative fimbriae clusters. These clusters may encode complete and 
1 functional pili, as some degree of homology was found between the other genes in the C. sakazakii

2 fimbriae clusters and the remaining components necessary for type-I pilus assembly (the minor tip

3 fibrillum FimG and fimbrial adhesin FimH). The presence of the putative fimbriae clusters in

4 Cronobacter species according to the CGH data is summarised in Table 3.

5 Type VI secretion system (T6SS) is a newly described system that may be involved in adherence,

6 cytotoxicity, host-cell invasion, growth inside macrophages and survival within the host. Five putative

7 T6SS clusters were identified in the genome of C. sakazakii BAA-894, some of which were

8 mentioned in (Kucerova, Clifton et al. 2010). Cluster 1 (ESA_00140 - ESA_00145) encodes most of

9 the proteins that are conserved across different T6SS clusters (a DotU homolog ESA_00141, Vgr

10 homolog ESA_00141 and a putative lipoprotein from the VC_A0113 family ESA_00145). However, most T6SS clusters typically encode from 12 to 25 proteins (Filloux, Hachani et al. 2008) and also encode a ClpV ATPase, which was not found in this cluster. In some instances, the genes encoding Vgr and DotU proteins are located outside the main T6SS locus, and their products might cooperate with proteins encoded in other loci. Cluster 2 (ESA_02035 - ESA_02040) includes genes encoding a Vgr-type protein (ESA_02035), lipoprotein from VC_A0113 family ESA_02038 and other genes homologous to proteins encoded in T6SS clusters. Cluster 3 (ESA_02735 - ESA_0240) contains genes encoding SciE-type protein (ESA_02736), Vgr-type protein (ESA_02739) and a protein homologous to phage gp7 protein, all of which are frequently found in T6SS clusters. However, this cluster is adjacent to a prophage fragment described in (Kucerova, Clifton et al. 2010) and due to the sequence similarities between T6SS and prophages it is difficult to conclude whether this cluster is a part of a T6SS. Cluster 4 (ESA_03899 - ESA_03946) is the longest and the most complete cluster of T6SS genes. Its 48 genes include all the components of T6SS typically conserved among different T6SS systems, such as genes encoding Vgr-type proteins (ESA_03905 and ESA_03917), IcmF-type protein (ESA_03945), DotU-type protein (ESA_03946), ClpV ATPase (ESA_03921), SciE-type protein (ESA_03925), Ser/Thr protein phosphatase (ESA_03927) and Ser/Thr protein kinase (ESA_03920). This cluster may encode a complete and functional T6SS. Cluster 5 
1 the conserved T6SS proteins. ESA_pESA3p05494 encodes DotU-like protein, ESA_pESA3p05495

2 encoded a protein with a C-terminal extension with similarity to $\mathrm{OmpA}$, a protein strongly associated

3 with virulence properties of Cronobacter. ESA_pESA3p05497 encodes a ClpV ATPase and

4 ESA_pESA3p05500 encodes a Vgr-like protein. The Clusters $1-5$ described here are putative T6SS

5 clusters. It remains to be determined whether they encode functional type VI secretion systems or

6 functional components of these.

8 Summary

9 The FAO/WHO 2004 expert committee recommended that research should be promoted to gain a 10 better understanding of the ecology, taxonomy, virulence and other characteristics of Cronobacter.

11 This has largely been undertaken by groups around the world. By understanding the organism better,

12 improved detection systems have been designed and commercialized. Currently microbiological

13 criteria for Cronobacter spp. are required for infant formulas with an intended target age $<6$ months.

14 A presence/absence test is applied to large volumes due to the low $(<1 \mathrm{cfu} / \mathrm{g})$ incidence of the organism in the product. Although the organism has been recovered from follow up formulas (infant formulas with intended target age $>6$ months) and weaning foods, there is currently insufficient epidemiological evidence to support the implementation of criteria for these products. Readers should consult the relevant Codex (2008) documents for details. With respect to clinical sources, MLST has revealed the organism is highly clonal and sources other than infant formula need to be considered; especially as a number of neonatal cases not attributable to PIF have been reported. Cronobacter does cause infections in all age groups. It is found in a wide range of foods, especially those of plant origin. While fortunately Cronobacter rarely causes severe meningitic and NEC infections, the heightened interest in the organism has resulted in improved regulatory control of products for the neonates and infants, as well as improved hygienic practices. Together these will reduce the risk of Cronobacter infection. 
1

\section{Acknowledgements}

The authors acknowledge the financial support of Nottingham Trent University for EK and SJ.

\section{References}

BALDWIN, A., LOUGHLIN, M., CAUBILLA-BARRON, J., KUCEROVA, E., MANNING, G., DOWSON, C. and FORSYTHE, S., 2009. Multilocus sequence typing of Cronobacter sakazakii and Cronobacter malonaticus reveals stable clonal structures with clinical significance which do not correlate with biotypes. BMC Microbiology, 9, 223.

BARDOWSKI, J., EHRLICH, S.D. and CHOPIN, A., 1994. BgIR protein, which belongs to the BglG family of transcriptional antiterminators, is involved in beta-glucoside utilization in Lactococcus lactis. Journal of Bacteriology, 176(18), 5681-5685.

BAR-OZ, B., PREMINGER, A., PELEG, O., BLOCK, C. and ARAD, I., 2001. Enterobacter sakazakii infection in the newborn. Acta Paediatrica (Oslo, Norway: 1992), 90(3), 356-358.

BARRON, J.C. and FORSYTHE, S.J., 2007. Dry stress and survival time of Enterobacter sakazakii and other Enterobacteriaceae in dehydrated powdered infant formula. Journal of Food Protection, 70(9), 2111-2117.

BEUCHAT, L.R., KIM, H., GURTLER, J.B., LIN, L.C., RYU, J.H. and RICHARDS, G.M., 2009. Cronobacter sakazakii in foods and factors affecting its survival, growth, and inactivation. International Journal of Food Microbiology, 136(2), 204-213.

BIERING, G., KARLSSON, S., CLARK, N.C., JONSDOTTIR, K.E., LUDVIGSSON, P. and STEINGRIMSSON, O., 1989. Three cases of neonatal meningitis caused by Enterobacter sakazakii in powdered milk. Journal of Clinical Microbiology, 27(9), 2054-2056.

BLOCK, C., PELEG, O., MINSTER, N., BAR-OZ, B., SIMHON, A., ARAD, I. and SHAPIRO, M., 2002. Cluster of neonatal infections in Jerusalem due to unusual biochemical variant of Enterobacter sakazakii. European Journal of Clinical Microbiology \& Infectious Diseases: official publication of the European Society of Clinical Microbiology, 21(8), 613-616.

BOWEN, A.B. and BRADEN, C.R., 2006. Invasive Enterobacter sakazakii disease in infants. Emerging Infectious Diseases, 12(8), 1185-1189.

BRENNER, D.J., 1974. DNA reassociation for the clinical differentiation of enteric bacteria. Public Health Laboratory, 32(4), 118-130.

BURDETTE, J.H. and SANTOS, C., 2000. Enterobacter sakazakii brain abscess in the neonate: the importance of neuroradiologic imaging. Pediatric radiology, 30(1), 33-34.

CARRANZA, P., HARTMANN, I., LEHNER, A., STEPHAN, R., GEHRIG, P., GROSSMANN, J., BARKOW-OESTERREICHER, S., ROSCHITZKI, B., EBERL, L. and RIEDEL, K., 2009.

Proteomic profiling of Cronobacter turicensis 3032, a food-borne opportunistic pathogen. Proteomics, 9(13), 3564-3579.

CAUBILLA-BARRON, J., HURRELL, E., TOWNSEND, S., CHEETHAM, P., LOC-CARRILLO, C., FAYET, O., PRERE, M.F. and FORSYTHE, S.J., 2007. Genotypic and phenotypic analysis of 
Enterobacter sakazakii strains from an outbreak resulting in fatalities in a neonatal intensive care unit in France. Journal of Clinical Microbiology, 45(12), 3979-3985.

CAUBILLA-BARRON, J., KUCEROVA, E., LOUGHLIN, M. and FORSYTHE, S.J., 2009.

Bacteriocidal preparation of powdered infant formula. Food Standards Agency http://www.foodbase.org.uk/results.php?f_category_id=\&f_report_id=395. Last accession date 19.8.10.

CHAP, J., JACKSON, P., SIQUEIRA, R., GASPAR, N., QUINTAS, C., PARK, J., OSAILI, T., SHAKER, R., JARADAT, Z., HARTANTYO, S.H., ABDULLAH SANI, N., ESTUNINGSIH, S. and FORSYTHE, S.J., 2009. International survey of Cronobacter sakazakii and other Cronobacter spp. in follow up formulas and infant foods. International Journal of Food Microbiology, 136(2), 185-188.

CLARK, N.C., HILL, B.C., O'HARA, C.M., STEINGRIMSSON, O. and COOKSEY, R.C., 1990. Epidemiologic typing of Enterobacter sakazakii in two neonatal nosocomial outbreaks. Diagnostic Microbiology and Infectious Disease, 13(6), 467-472.

CODEX ALIMENTARIUS COMMISSION (CAC), 2008. Code of hygienic practice for powdered formulae for infants and young children. CAC/RCP.

CZERWICKA, M., FORSYTHE, S.J., BYCHOWSKA, A., DZIADZIUSZKO, H., KUNIKOWSKA, D., STEPNOWSKI, P. and KACZYNSKI, Z., 2010. Structure of the O-polysaccharide isolated from Cronobacter sakazakii 767. Carbohydrate Research, 345(7), 908-913.

EGGERS, C.T., MURRAY, I.A., DELMAR, V.A., DAY, A.G. and CRAIK, C.S., 2004. The periplasmic serine protease inhibitor ecotin protects bacteria against neutrophil elastase. The Biochemical Journal, 379(Pt 1), 107-118.

FAO/WHO, 2004. Workshop on Enterobacter sakazakii and other microorganisms in powdered infant formula, Geneva, 2-5 February 2004.

http://www.who.int/foodsafety/micro/jemra/meetings/feb2004/en/index.html. Last accessed 19.8.10.

FAO/WHO, 2006. Expert meeting on Enterobacter sakazakii and Salmonella in powdered infant formula, Rome, 16-20 January 2006.

http://www.who.int/foodsafety/micro/jemra/meetings/jan2006/en/index.html. Last accessed 19.8.10.

FAO/WHO, 2008. Enterobacter sakazakii (Cronobacter spp.) in powdered follow-up formulae.

Microbiological Risk Assessment Series No. 15. Rome. 90pp.

http://www.who.int/foodsafety/publications/micro/mra_followup/en/. Last accessed 19.1.11

FARMER, J.J., 1980. Enterobacter sakazakii: a new species of "Enterobacteriaceae" isolated from clinical specimens. Intl J System Bacteriol, 30, 569-584.

FILLOUX, A., HACHANI, A. and BLEVES, S., 2008. The bacterial type VI secretion machine: yet another player for protein transport across membranes. Microbiology (Reading, England), 154(Pt 6), $1570-1583$.

FRIEDEMANN, M., 2007. Enterobacter sakazakii in food and beverages (other than infant formula and milk powder). International Journal of Food Microbiology, 116(1), 1-10.

GURTLER, J.B., KORNACKI, J.L. and BEUCHAT, L.R., 2005. Enterobacter sakazakii: a coliform of increased concern to infant health. International Journal of Food Microbiology, 104(1), 1-34.

HARRIS, L.S. and ORIEL, P.J., 1989. Heteropolysaccharide produced by Enterobacter sakazakii. United States Patent number 4,806,636.

HEALY, B., HUYNH, S., MULLANE, N., O'BRIEN, S., IVERSEN, C., LEHNER, A., STEPHAN, R., PARKER, C.T. and FANNING, S., 2009. Microarray-based comparative genomic indexing of the 
Cronobacter genus (Enterobacter sakazakii). International Journal of Food Microbiology, 136(2), 159-164.

HENRY, M.C. and MOSS, R.L., 2009. Necrotizing enterocolitis. Annual Review of Medicine, 60 , 111-124.

HIMELRIGHT, I., HARRIS, E., LORCH, V. and ANDERSON, M., 2002. Enterobacter sakazakii infections associated with the use of powdered infant formula, Tennessee, 2001. J Am Med Assoc, 287, 2204-2205.

HURRELL, E., KUCEROVA, E., LOUGHLIN, M., CAUBILLA-BARRON, J. and FORSYTHE, S.J., 2009a. Biofilm formation on enteral feeding tubes by Cronobacter sakazakii, Salmonella serovars and other Enterobacteriaceae. International Journal of Food Microbiology, 136(2), 227-231.

HURRELL, E., KUCEROVA, E., LOUGHLIN, M., CAUBILLA-BARRON, J., HILTON, A., ARMSTRONG, R., SMITH, C., GRANT, J., SHOO, S. and FORSYTHE, S., 2009b. Neonatal enteral feeding tubes as loci for colonisation by members of the Enterobacteriaceae. BMC Infectious Diseases, 9, 146.

IVERSEN, C. and FORSYTHE, S., 2003. Risk profile of Enterobacter sakazakii, an emergent pathogen associated with infant milk formula. Trends in Food Science \& Technology, 14(11), 443 454.

IVERSEN, C., LANCASHIRE, L., WADDINGTON, M., FORSYTHE, S. and BALL, G., 2006. Identification of Enterobacter sakazakii from closely related species: the use of artificial neural networks in the analysis of biochemical and 16S rDNA data. BMC Microbiology, 6, 28.

IVERSEN, C., LEHNER, A., MULLANE, N., BIDLAS, E., CLEENWERCK, I., MARUGG, J., FANNING, S., STEPHAN, R. and JOOSTEN, H., 2007. The taxonomy of Enterobacter sakazakii: proposal of a new genus Cronobacter gen. nov. and descriptions of Cronobacter sakazakii comb. nov. Cronobacter sakazakii subsp. sakazakii, comb. nov., Cronobacter sakazakii subsp. malonaticus subsp. nov., Cronobacter turicensis sp. nov., Cronobacter muytjensii sp. nov., Cronobacter dublinensis sp. nov. and Cronobacter genomospecies 1. BMC Evolutionary Biology, 7, 64.

IVERSEN, C., MULLANE, N., MCCARDELL, B., TALL, B.D., LEHNER, A., FANNING, S., STEPHAN, R. and JOOSTEN, H., 2008. Cronobacter gen. nov., a new genus to accommodate the biogroups of Enterobacter sakazakii, and proposal of Cronobacter sakazakii gen. nov., comb. nov., Cronobacter malonaticus sp. nov., Cronobacter turicensis sp. nov., Cronobacter muytjensii sp. nov., Cronobacter dublinensis sp. nov., Cronobacter genomospecies 1, and of three subspecies, Cronobacter dublinensis subsp. dublinensis subsp. nov., Cronobacter dublinensis subsp. lausannensis subsp. nov. and Cronobacter dublinensis subsp. lactaridi subsp. nov. International Journal of Systematic and Evolutionary Microbiology, 58, 1442-1447.

IVERSEN, C., WADDINGTON, M., FARMER, J.J.,3RD and FORSYTHE, S.J., 2006. The biochemical differentiation of Enterobacter sakazakii genotypes. BMC Microbiology, 6, 94.

IVERSEN, C., WADDINGTON, M., ON, S.L. and FORSYTHE, S., 2004. Identification and phylogeny of Enterobacter sakazakii relative to Enterobacter and Citrobacter species. Journal of Clinical Microbiology, 42(11), 5368-5370.

IZARD, D., RICHAR, C. and LECLERC, H., 1983. DNA relatedness between Enterobacter sakazakii and other members of the genus Enterobacter. Annales de l'Institut Pasteur.Microbiologie, 134(3, Supplement 1), 241-245.

KANDHAI, M.C., REIJ, M.W., GORRIS, L.G., GUILLAUME-GENTIL, O. and VAN SCHOTHORST, M., 2004. Occurrence of Enterobacter sakazakii in food production environments and households. Lancet, 363(9402), 39-40. 
KIM, H., RYU, J.H. and BEUCHAT, L.R., 2007. Effectiveness of disinfectants in killing Enterobacter sakazakii in suspension, dried on the surface of stainless steel, and in a biofilm. Applied and Environmental Microbiology, 73(4), 1256-1265.

KIM, K., JANG, S.S., KIM, S.K., PARK, J.H., HEU, S. and RYU, S., 2008. Prevalence and genetic diversity of Enterobacter sakazakii in ingredients of infant foods. International Journal of Food Microbiology, 122(1-2), 196-203.

KIM, K.P. and LOESSNER, M.J., 2008. Enterobacter sakazakii invasion in human intestinal Caco-2 cells requires the host cell cytoskeleton and is enhanced by disruption of tight junction. Infection and Immunity, 76(2), 562-570.

KLINE, K.A., DODSON, K.W., CAPARON, M.G. and HULTGREN, S.J., 2010. A tale of two pili: assembly and function of pili in bacteria. Trends in Microbiology, 18(5), 224-232.

KLINE, M.W., 1988. Citrobacter meningitis and brain abscess in infancy: Epidemiology, pathogenesis, and treatment. The Journal of Pediatrics, 113(3), 430-434.

KOTHARY, M.H., MCCARDELL, B.A., FRAZAR, C.D., DEER, D. and TALL, B.D., 2007. Characterization of the zinc-containing metalloprotease encoded by $z p x$ and development of a speciesspecific detection method for Enterobacter sakazakii. Applied and Environmental Microbiology, 73(13), 4142-4151.

KUCEROVA, E., CLIFTON, S.W., XIA, X.Q., LONG, F., PORWOLLIK, S., FULTON, L., FRONICK, C., MINX, P., KYUNG, K., WARREN, W., FULTON, R., FENG, D., WOLLAM, A., SHAH, N., BHONAGIRI, V., NASH, W.E., HALLSWORTH-PEPIN, K., WILSON, R.K., MCCLELLAND, M. and FORSYTHE, S.J., 2010. Genome sequence of Cronobacter sakazakii BAA894 and comparative genomic hybridization analysis with other Cronobacter species. PloS One, 5(3), e9556.

LAI, K.K., 2001. Enterobacter sakazakii infections among neonates, infants, children, and adults. Case reports and a review of the literature. Medicine, 80(2), 113-122.

LEHNER, A., RIEDEL, K., EBERL, L., BREEUWER, P., DIEP, B. and STEPHAN, R., 2005. Biofilm formation, extracellular polysaccharide production, and cell-to-cell signaling in various Enterobacter sakazakii strains: aspects promoting environmental persistence. Journal of Food Protection, 68(11), 2287-2294.

LIMA-MENDEZ, G., VAN HELDEN, J., TOUSSAINT, A. and LEPLAE, R., 2008. Prophinder: a computational tool for prophage prediction in prokaryotic genomes. Bioinformatics (Oxford, England), 24(6), 863-865.

LUCAS, A. and COLE, T.J., 1990. Breast milk and neonatal necrotising enterocolitis. Lancet, 336(8730), 1519-1523.

MACLEAN, L.L., PAGOTTO, F., FARBER, J.M. and PERRY, M.B., 2009a. Structure of the antigenic repeating pentasaccharide unit of the LPS O-polysaccharide of Cronobacter sakazakii implicated in the Tennessee outbreak. Biochemistry and cell biology = Biochimie et Biologie Cellulaire, 87(2), 459-465.

MACLEAN, L.L., PAGOTTO, F., FARBER, J.M. and PERRY, M.B., 2009b. The structure of the Oantigen in the endotoxin of the emerging food pathogen Cronobacter (Enterobacter) muytjensii strain 3270. Carbohydrate Research, 344(5), 667-671.

MITTAL, R., WANG, Y., HUNTER, C.J., GONZALEZ-GOMEZ, I. and PRASADARAO, N.V., 2009. Brain damage in newborn rat model of meningitis by Enterobacter sakazakii: a role for outer 
membrane protein A. Laboratory investigation; a journal of technical methods and pathology, 89(3), 263-277.

MOHAN NAIR, M.K. and VENKITANARAYANAN, K.S., 2006. Cloning and sequencing of the ompA gene of Enterobacter sakazakii and development of an ompA-targeted PCR for rapid detection of Enterobacter sakazakii in infant formula. Applied and Environmental Microbiology, 72(4), 25392546.

MULLANE, N., O'GAORA, P., NALLY, J.E., IVERSEN, C., WHYTE, P., WALL, P.G. and FANNING, S., 2008. Molecular analysis of the Enterobacter sakazakii O-antigen gene locus. Applied and Environmental Microbiology, 74(12), 3783-3794.

MULLANE, N.R., RYAN, M., IVERSEN, C., MURPHY, M., O'GAORA, P., QUINN, T., WHYTE, P., WALL, P.G. and FANNING, S., 2008. Development of multiple-locus variable-number tandemrepeat analysis for the molecular subtyping of Enterobacter sakazakii. Applied and Environmental Microbiology, 74(4), 1223-1231.

MUYTJENS, H.L. and KOLLEE, L.A., 1990. Enterobacter sakazakii meningitis in neonates: causative role of formula? The Pediatric Infectious Disease Journal, 9(5), 372-373.

MUYTJENS, H.L., ROELOFS-WILLEMSE, H. and JASPAR, G.H., 1988. Quality of powdered substitutes for breast milk with regard to members of the family Enterobacteriaceae. Journal of Clinical Microbiology, 26(4), 743-746.

MUYTJENS, H.L., VAN DER ROS-VAN DE REPE, J. and VAN DRUTEN, H.A., 1984. Enzymatic profiles of Enterobacter sakazakii and related species with special reference to the alpha-glucosidase reaction and reproducibility of the test system. Journal of Clinical Microbiology, 20(4), 684-686.

MUYTJENS, H.L., ZANEN, H.C., SONDERKAMP, H.J., KOLLEE, L.A., WACHSMUTH, I.K. and FARMER, J.J.,3RD, 1983. Analysis of eight cases of neonatal meningitis and sepsis due to Enterobacter sakazakii. Journal of Clinical Microbiology, 18(1), 115-120.

NAZAROWEC-WHITE, M. and FARBER, J.M., 1999. Phenotypic and genotypic typing of food and clinical isolates of Enterobacter sakazakii. Journal of Medical Microbiology, 48(6), 559-567.

OSAILI, T. and FORSYTHE, S., 2009. Desiccation resistance and persistence of Cronobacter species in infant formula. International Journal of Food Microbiology, 136(2), 214-220.

PAGOTTO, F.J., NAZAROWEC-WHITE, M., BIDAWID, S. and FARBER, J.M., 2003.

Enterobacter sakazakii: infectivity and enterotoxin production in vitro and in vivo. Journal of Food Protection, 66(3), 370-375.

PITOUT, J.D., MOLAND, E.S., SANDERS, C.C., THOMSON, K.S. and FITZSIMMONS, S.R., 1997. Beta-lactamases and detection of beta-lactam resistance in Enterobacter spp. Antimicrobial Agents and Chemotherapy, 41(1), 35-39.

POIREL, L., NORDMANN, P., DE CHAMPS, C. and ELOY, C., 2007. Nosocomial spread of QnrAmediated quinolone resistance in Enterobacter sakazakii. International Journal of Antimicrobial Agents, 29(2), 223-224.

RICHARDSON, A.N., LAMBERT, S. and SMITH, M.A., 2009. Neonatal mice as models for Cronobacter sakazakii infection in infants. Journal of Food Protection, 72(11), 2363-2367.

RIEDEL, K. and LEHNER, A., 2007. Identification of proteins involved in osmotic stress response in Enterobacter sakazakii by proteomics. Proteomics, 7(8), 1217-1231.

SANDERS, W.E.,JR and SANDERS, C.C., 1997. Enterobacter spp.: pathogens poised to flourish at the turn of the century. Clinical Microbiology Reviews, 10(2), 220-241. 
SCHEEPE-LEBERKUHNE, M. and WAGNER, F., 1986. Optimization and preliminary characterization of an exopolysaccharide synthezised by Enterobacter sakazakii. Biotechnol. Lett., 8, 695-700.

SCHMID, M., IVERSEN, C., GONTIA, I., STEPHAN, R., HOFMANN, A., HARTMANN, A., JHA, B., EBERL, L., RIEDEL, K. and LEHNER, A., 2009. Evidence for a plant-associated natural habitat for Cronobacter spp. Research in Microbiology, 160(8), 608-614.

SIMMONS, B.P., GELFAND, M.S., HAAS, M., METTS, L. and FERGUSON, J., 1989.

Enterobacter sakazakii infections in neonates associated with intrinsic contamination of a powdered infant formula. Infection control and hospital epidemiology: the official journal of the Society of Hospital Epidemiologists of America, 10(9), 398-401.

STOCK, I. and WIEDEMANN, B., 2002. Natural antibiotic susceptibility of Enterobacter amnigenus, Enterobacter cancerogenus, Enterobacter gergoviae and Enterobacter sakazakii strains. Clinical microbiology and infection: the official publication of the European Society of Clinical Microbiology and Infectious Diseases, 8(9), 564-578.

SZAFRANEK, J., CZERWICKA, M., KUMIRSKA, J., PASZKIEWICZ, M. and LOJKOWSKA, E., 2005. Repeating unit structure of Enterobacter sakazakii ZORB 741 O-Polysaccharide. Polish J. Chem., 79, 287-295.

TOWNSEND, S., CAUBILLA BARRON, J., LOC-CARRILLO, C. and FORSYTHE, S., 2007. The presence of endotoxin in powdered infant formula milk and the influence of endotoxin and Enterobacter sakazakii on bacterial translocation in the infant rat. Food Microbiology, 24(1), 67-74.

TOWNSEND, S., HURRELL, E. and FORSYTHE, S., 2008. Virulence studies of Enterobacter sakazakii isolates associated with a neonatal intensive care unit outbreak. BMC Microbiology, 8, 64 .

TOWNSEND, S.M., HURRELL, E., GONZALEZ-GOMEZ, I., LOWE, J., FRYE, J.G., FORSYTHE, S. and BADGER, J.L., 2007. Enterobacter sakazakii invades brain capillary endothelial cells, persists in human macrophages influencing cytokine secretion and induces severe brain pathology in the neonatal rat. Microbiology (Reading, England), 153, 3538-3547.

VAN ACKER, J., DE SMET, F., MUYLDERMANS, G., BOUGATEF, A., NAESSENS, A. and LAUWERS, S., 2001. Outbreak of necrotizing enterocolitis associated with Enterobacter sakazakii in powdered milk formula. Journal of Clinical Microbiology, 39(1), 293-297.

WEIR, E., 2002. Powdered infant formula and fatal infection with Enterobacter sakazakii. CMAJ : Canadian Medical Association journal = journal de l'Association medicale canadienne, 166(12), 1570 .

World Health Organisation. Guidelines for the safe preparation, storage and handling of powdered infant formula. http://www.who.int/foodsafety/publications/micro/pif2007/en/. Last accessed 19.1.11

WILLIS, J. and ROBINSON, J.E., 1988. Enterobacter sakazakii meningitis in neonates. The Pediatric infectious Disease Journal, 7(3), 196-199. 
1 Table 1 Cronobacter species groupings, updated from (Baldwin, Loughlin et al. 2009).

2

\begin{tabular}{lccc}
\hline Cronobacter species & 16S cluster & Biotypes & MLST sequence types \\
\hline C. sakazakii & & & $1,2-4,8,9,12-18,20-$ \\
C. malonaticus & 1 & $1,2-4,7,8,11,13$ & $23,31,40,41,45,47,50,52$ \\
C. turicensis & 1 & $5,9,14$ & $7,10,11,25,26,29,53$ \\
C. muytjensii & 2 & 16 & $5,19,24,32,35,37$ \\
C. dublinensis & 3 & 15 & $28,33,34,44,49$ \\
Cronobacter genomospecies 1 & 4 & $6,10,12$ & $27,36,38,39,42,43,46$ \\
\hline
\end{tabular}

3

4

5 
2 Table 2 Distribution of gene clusters across the Cronobacter genus

3
Gene loci
ESA 00257 - ESA 00258
ESA_01116 - ESA_01119
ESA 01448 - ESA 01450
ESA_02125 - ESA_02129
ESA 02538 - ESA 02542
ESA_02544 - ESA_02547
ESA 02549 - ESA 02553
ESA_02616 - ESA_02618
ESA 02795 - ESA 02799
ESA_03301 - ESA_03320
ESA 03609 - ESA 03613
ESA_04067 -ESA_04073
ESA_04101 -ESA_04106

Description
Toxin/antitoxin RelE/RelB
ABC-type multidrug efflux
Fatty acid desaturases
Ecotin (ESA_02129)
Fimbriae
Beta-glucosides metabolism
Multidrug efflux system
Mannosyl-D-glycerate uptake
Fimbriae
Mannose metabolism
Mannose metabolism
Fimbriae
Cell wall biogenesis

C. malonaticus

NO

NO

NO

YES

NO

YES

YES

YES

NO

NO

NO

NO

NO

C. turicensis
NO
NO
YES
NO$^{1}$
NO
NO
YES
NO
NO
NO
NO
NO
YES

$\begin{array}{cc}\text { C. muytjensii } & \text { C. dublinensis } \\ \text { NO } & \text { NO } \\ \text { NO } & \text { NO } \\ \text { YES } & \text { YES } \\ \text { NO } & \text { NO }^{1} \\ \text { NO } & \text { NO } \\ \text { YES } & \text { YES } \\ \text { NO } & \text { YES } \\ \text { YES } & \text { YES } \\ \text { NO } & \text { NO } \\ \text { NO } & \text { NO } \\ \text { NO } & \text { NO } \\ \text { NO } & \text { NO } \\ \text { YES } & \text { YES }\end{array}$

\section{5}

$6 \quad{ }^{1}$ The presence/absence status in Cronobacter species relates to the gene for ecotin

$7 \quad{ }^{2}$ See main text for details about absence/presence of particular genes from this cluster 
1 Table 3 C. sakazakii BAA-894 fimbrial clusters and their presence in other Cronobacter strains

\begin{tabular}{|c|c|c|c|c|c|c|c|c|c|c|c|}
\hline \multirow{2}{*}{ Locus tag } & \multirow{2}{*}{ Gene Product } & \multicolumn{6}{|c|}{ C. sakazakii } & \multirow{2}{*}{ C. malonaticus } & \multirow{2}{*}{ C. turicensis } & \multirow{2}{*}{ C. muytjensii } & \multirow{2}{*}{ C. dublinensis } \\
\hline & & $1^{1}$ & 2 & 20 & 701 & 767 & 696 & & & & \\
\hline ESA_01976 & Pilin FimA & -1 & 1 & -1 & -1 & -1 & -1 & -1 & -1 & -1 & -1 \\
\hline ESA_01975 & Chaperone FimC & -1 & 0 & -1 & -1 & -1 & -1 & -1 & -1 & -1 & -1 \\
\hline ESA_01974 & Usher FimD & -1 & 1 & -1 & -1 & -1 & -1 & -1 & -1 & -1 & -1 \\
\hline ESA_01973 & Pilin FimA & -1 & 1 & -1 & -1 & -1 & -1 & -1 & -1 & -1 & -1 \\
\hline ESA_01972 & Pilin FimA & -1 & 1 & -1 & -1 & -1 & -1 & -1 & -1 & -1 & -1 \\
\hline ESA_01971 & Pilin FimA & -1 & 1 & -1 & -1 & -1 & -1 & -1 & -1 & -1 & -1 \\
\hline ESA_01970 & Pilin FimA & -1 & 1 & -1 & -1 & -1 & -1 & -1 & -1 & -1 & -1 \\
\hline ESA_02538 & Pilin FimA & $1^{2}$ & 1 & 1 & 1 & 1 & 1 & -1 & -1 & -1 & -1 \\
\hline ESA_02539 & Chaperone FimC & 0 & 1 & 1 & 0 & 0 & 1 & -1 & -1 & -1 & -1 \\
\hline ESA_02540 & Usher FimD & 1 & 1 & 1 & 1 & 1 & 1 & -1 & -1 & -1 & -1 \\
\hline ESA_02541 & Pilin FimA (FimH) & 1 & 1 & 1 & 1 & 1 & 1 & -1 & -1 & -1 & -1 \\
\hline ESA_02542 & Putative minor component FimG & 1 & 1 & 1 & 1 & 1 & 1 & -1 & -1 & -1 & -1 \\
\hline ESA_02799 & Putative fimbrial protein & 1 & 1 & 0 & 0 & 0 & 0 & 0 & -1 & -1 & -1 \\
\hline ESA_02798 & Chaperone FimC & 1 & 1 & 1 & 1 & 1 & 1 & -1 & -1 & -1 & -1 \\
\hline ESA_02797 & Usher FimD & 1 & 1 & 1 & 1 & 1 & 1 & -1 & -1 & -1 & -1 \\
\hline ESA_02796 & Pilin FimA & 1 & 1 & 1 & 1 & 1 & 1 & -1 & -1 & -1 & -1 \\
\hline ESA_02795 & Fimbrial protein & 1 & 1 & 1 & 1 & 1 & 1 & -1 & -1 & -1 & -1 \\
\hline ESA_04067 & Putative fimbrial protein & 0 & 1 & 1 & 1 & 0 & 1 & -1 & -1 & -1 & -1 \\
\hline ESA_04068 & Fimbrial protein & -1 & 1 & 0 & -1 & -1 & 0 & -1 & -1 & -1 & -1 \\
\hline ESA_04069 & Fimbrial protein & 0 & 1 & 1 & 1 & 1 & 1 & -1 & -1 & -1 & -1 \\
\hline ESA_04070 & Fimbrial protein & 0 & 1 & 1 & 1 & 1 & 1 & -1 & -1 & -1 & -1 \\
\hline ESA_04071 & Usher FimD & 1 & 1 & 1 & 1 & 1 & 1 & -1 & -1 & -1 & -1 \\
\hline ESA_04072 & Chaperone FimC & 1 & 1 & 1 & 1 & 1 & 1 & 0 & 0 & -1 & -1 \\
\hline ESA_04073 & Fimbrial protein & 0 & 1 & 1 & 1 & 1 & 1 & -1 & -1 & -1 & -1 \\
\hline
\end{tabular}

2 Footnote: ${ }^{1}$ C. sakazakii strain number, see (Kucerova, Clifton et al. 2010) for details. ${ }^{2}$ According to $\mathrm{CGH}$ analysis $1=$ Present, $0=$ Intermediate, $-1=$

3 Absent. 
1 Table 4 Iron uptake systems in C. sakazakii BAA-894 and other Cronobacter strains.

2

\begin{tabular}{|c|c|c|c|c|c|c|c|c|c|c|c|c|}
\hline \multirow{2}{*}{ Gene } & \multirow{2}{*}{ Esak homologue (BLAST) } & \multirow{2}{*}{ Locus Tag } & \multirow[b]{2}{*}{$1^{1}$} & \multicolumn{4}{|c|}{ C. sakazakii } & \multirow[b]{2}{*}{696} & \multirow{2}{*}{ C. malonaticus } & \multirow{2}{*}{ C. turicensis } & \multirow{2}{*}{ C. muytjensii } & \multirow{2}{*}{ C. dublinensis } \\
\hline & & & & 2 & 20 & 701 & 767 & & & & & \\
\hline \multicolumn{13}{|c|}{ Enterobactin synthesis - non ribosomal peptide synthesis pathway } \\
\hline entA & 2,3-dihydroxybenzoate-2,3-dehydrogenase & ESA_00799 & $1^{2}$ & 1 & 1 & 1 & 1 & 1 & 1 & 1 & 0 & 1 \\
\hline ent $\mathrm{B}$ & hypothetical protein ESA_00798 & ESA_00798 & 1 & 1 & 1 & 1 & 1 & 1 & 1 & 1 & 1 & 1 \\
\hline entC & hypothetical protein ESA_00796 & ESA_00797 & 0 & 1 & 0 & 0 & 0 & 0 & 1 & 1 & 1 & 1 \\
\hline ent $\mathrm{D}$ & hypothetical protein ESA_02731 & ESA_02731 & 1 & 1 & 1 & 1 & 1 & 0 & 0 & 1 & 0 & 0 \\
\hline entE & enterobactin synthase subunit $E$ & ESA_02729 & 0 & 1 & 0 & 0 & 1 & 1 & 0 & 1 & 0 & 1 \\
\hline entF & enterobactin synthase subunit $F$ & ESA_02727 & 1 & 1 & 0 & 0 & 1 & 0 & 1 & 1 & 0 & 1 \\
\hline ents & enterobactin exporter EntS & ESA_00794 & 1 & 1 & 1 & 1 & 1 & 1 & 1 & 1 & 1 & 1 \\
\hline \multicolumn{13}{|c|}{ Enterobactin receptor and transporters } \\
\hline fepA & outer membrane receptor FepA & ESA_02730 & 1 & 1 & 1 & 1 & 1 & 1 & 1 & 1 & 1 & 1 \\
\hline fepB & iron-enterobactin transporter & ESA_00796 & 1 & 1 & 1 & 1 & 1 & 0 & 1 & 1 & 1 & 1 \\
\hline fepC & hypothetical protein ESA_00791 & ESA_00791 & 1 & 1 & 1 & 1 & 1 & 0 & 1 & 1 & 1 & 1 \\
\hline fepD & iron-enterobactin transporter & ESA_00793 & 1 & 1 & 0 & 0 & 1 & 0 & 1 & 1 & 1 & 1 \\
\hline fepE & ferric enterobactin transport protein FepE & ESA_00459 & 1 & 1 & 1 & 1 & 1 & 1 & 0 & 0 & 0 & -1 \\
\hline fepG & iron-enterobactin transporter permease & ESA_00792 & 1 & 1 & 0 & 1 & 1 & 0 & 1 & 1 & 1 & 1 \\
\hline \multicolumn{13}{|c|}{ Salmochelin synthesis } \\
\hline iroB & salmochelin siderophore system & No match & NA & NA & NA & NA & NA & NA & NA & NA & NA & NA \\
\hline iroc & salmochelin siderophore system & No match & NA & NA & NA & NA & NA & NA & NA & NA & NA & NA \\
\hline iroD & enterobactin/ferric enterobactin esterase & No match & NA & NA & NA & NA & NA & NA & NA & NA & NA & NA \\
\hline iroE & IroE protein & No match & NA & NA & NA & NA & NA & NA & NA & NA & NA & NA \\
\hline iroN & outer membrane receptor FepA & ESA_01552 & 1 & 1 & 1 & 1 & 1 & 1 & 0 & 0 & 1 & 1 \\
\hline \multicolumn{13}{|c|}{ Aerobactin synthesis and receptor } \\
\hline iucA & hypothetical protein ESA_pESA3p05547 & ESA_pESA3p05547 & 1 & 1 & 0 & 0 & 1 & 1 & 1 & 1 & -1 & 1 \\
\hline$i u c \mathrm{~B}$ & hypothetical protein ESA_pESA3p05548 & ESA_pESA3p05548 & 1 & 1 & 0 & 0 & 0 & 0 & 1 & 1 & -1 & 1 \\
\hline iucC & hypothetical protein ESA_pESA3p05549 & ESA_pESA3p05549 & 0 & 0 & 0 & 0 & 0 & 0 & 1 & 1 & -1 & 0 \\
\hline$i u c \mathrm{D}$ & hypothetical protein ESA_pESA3p05550 & ESA_pESA3p05550 & 1 & 1 & 0 & 0 & 1 & 1 & 1 & 1 & -1 & 1 \\
\hline iutA & hypothetical protein ESA_pESA3p05551 & ESA_pESA3p05551 & 1 & 1 & 1 & 1 & 1 & 1 & 1 & 0 & -1 & 0 \\
\hline
\end{tabular}


Other iron uptake genes

feS enterobactin/ferric enterobactin esterase

fhuA ferrichrome outer membrane transporter

fhuB iron-hydroxamate transporter permease

fhuD iron-hydroxamate transporter

fpvA ferrichrome outer membrane transporter

fur ferric uptake regulator

ibpA heat shock protein IbpA

$i b p \mathrm{~B}$ heat shock chaperone IbpB

$\begin{array}{cccccc}\text { No match } & \text { NA } & \text { NA } & \text { NA } & \text { NA } & \text { NA } \\ \text { ESA_03190 } & 1 & 1 & 1 & 1 & 1 \\ \text { ESA_03187 } & 1 & 1 & 1 & 1 & 1 \\ \text { ESA_03188 } & 1 & 1 & 1 & 1 & 1 \\ \text { No match } & \text { NA } & \text { NA } & \text { NA } & \text { NA } & \text { NA } \\ \text { No match } & \text { NA } & \text { NA } & \text { NA } & \text { NA } & \text { NA } \\ \text { ESA_03960 } & 1 & 1 & 1 & 1 & 0 \\ \text { ESA_03959 } & 1 & 1 & 1 & 1 & 1\end{array}$

NA
1
1
1
NA
NA
1
1

$\begin{array}{ccc}\text { NA } & \text { NA } & \text { NA } \\ 0 & -1 & 1 \\ 1 & 1 & 1 \\ 1 & 1 & 1 \\ \text { NA } & \text { NA } & \text { NA } \\ \text { NA } & \text { NA } & \text { NA } \\ 1 & 1 & 1 \\ 1 & 1 & 1\end{array}$

4 Footnote: ${ }^{1}$ C. sakazakii strain number, see (Kucerova, Clifton et al. 2010) for details ${ }^{2}$ According to CGH analysis $1=$ Present, $0=$ Intermediate, $-1=$ Absent. 
1 Figure 1. 16S rDNA gene neighbour joining phylogenetic tree of Cronobacter genus.

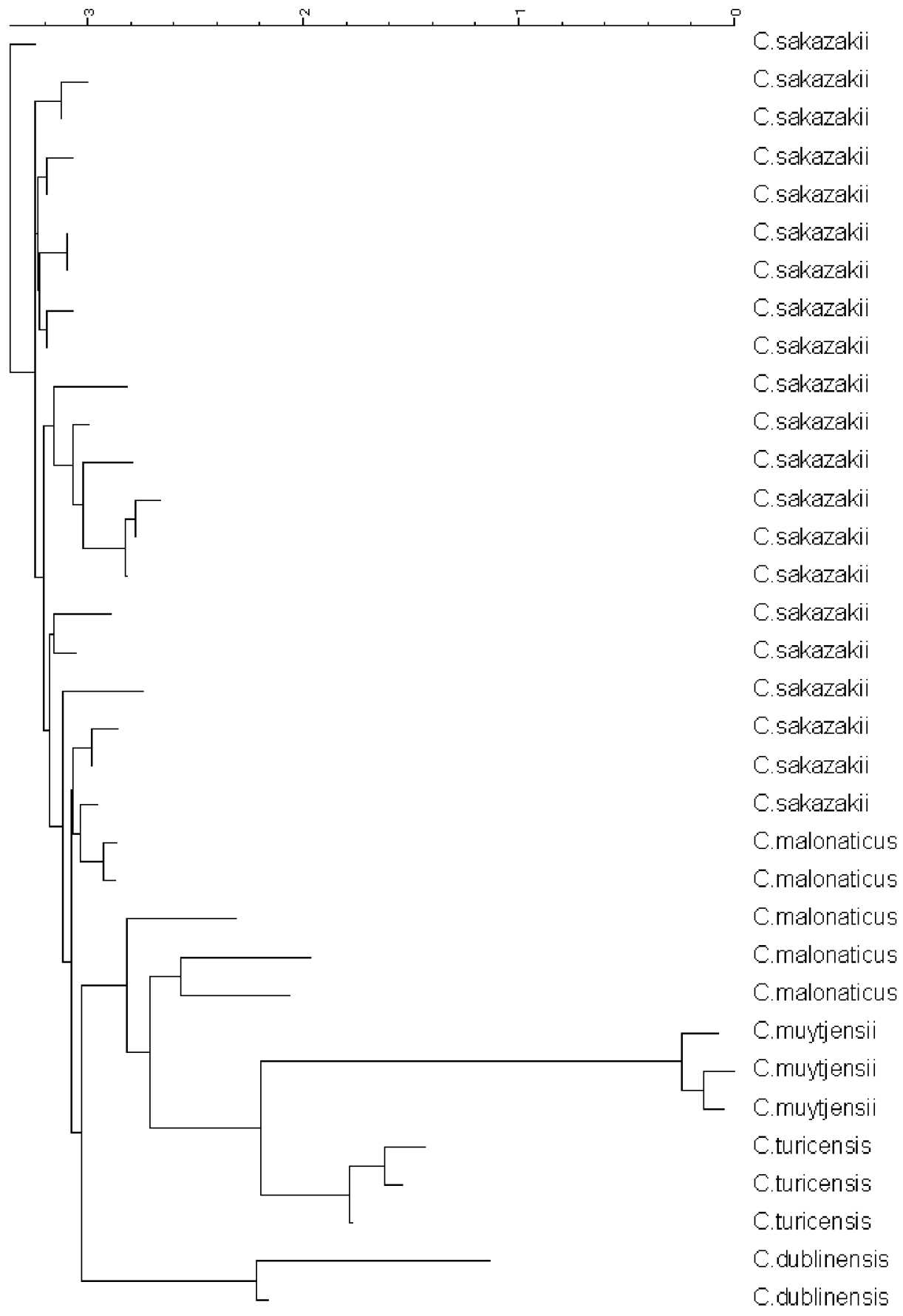


1 Figure 2. Mulitlocus sequence typing (7 loci, $3036 \mathrm{nt}$ ) gene neighbour joining phylogenetic tree of 2 Cronobacter genus.

3 


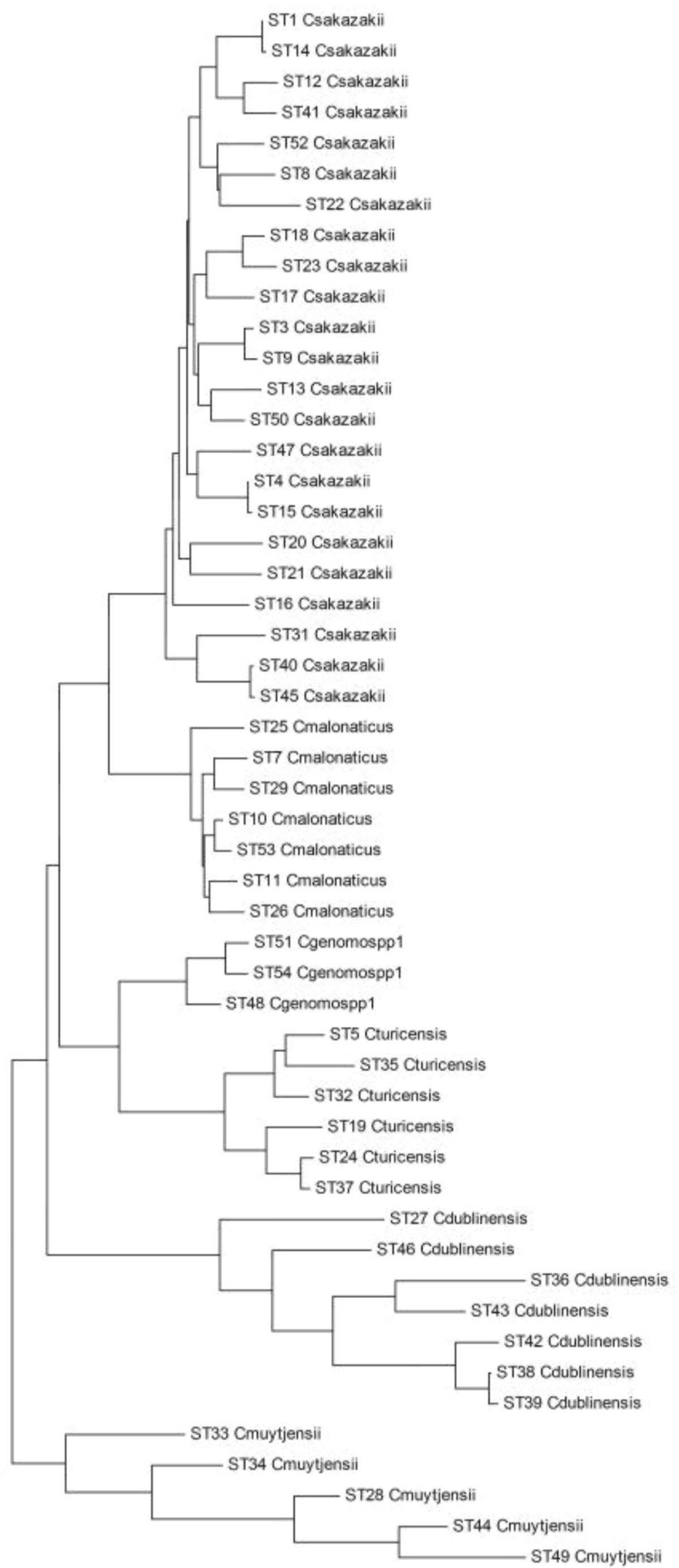


